Review

\title{
Fluorescent probe for mercury ion imaging analysis: Strategies and applications
}

\author{
Yue Wang ${ }^{\text {a,e }}$, Li Zhang ${ }^{\text {a,e }}$, Xiaoyue Han ${ }^{\text {a }}$, Liangwei Zhang ${ }^{\text {a,d, }}$, Xiaoyan Wang ${ }^{\mathrm{b}}$, \\ Lingxin Chen ${ }^{\text {a, b, c, d,* }}$ \\ ${ }^{a}$ CAS Key Laboratory of Coastal Environmental Processes and Ecological Remediation, Shandong Key Laboratory of Coastal Environmental Processes, Yantai Institute of \\ Coastal Zone Research, Chinese Academy of Sciences, Yantai 264003, China \\ bchool of Pharmacy, Binzhou Medical University, Yantai 264003, China \\ ${ }^{\mathrm{c}}$ Laboratory for Marine Biology and Biotechnology, Pilot National Laboratory for Marine Science and Technology, Qingdao 266237, China \\ d Center for Ocean Mega-Science, Chinese Academy of Sciences, Qingdao 266071, China \\ ${ }^{\mathrm{e}}$ University of Chinese Academy of Sciences, Beijing 100049, China
}

\section{A R T I C L E I N F O}

\section{Keywords:}

Fluorescent probe

Mercury ions

Fluorescence analysis

Environmental analysis

\begin{abstract}
A B S T R A C T
Environmental pollution problem, especially mercury ions $\left(\mathrm{Hg}^{2+}\right)$ pollution, seriously threatens the organism health. Numerous researches have revealed that even extremely low concentration of $\mathrm{Hg}^{2+}$ can severely damage the organisms. Therefore, it is essential for real-time detection of $\mathrm{Hg}^{2+}$. Fluorescent probe technology with great advantages has become the preferred technique for environmental detection and in vivo analysis of $\mathrm{Hg}^{2+}$. In recent years, lots of contributions have been committed to designing and synthesizing novel fluorescent probes for environmental pollutant $\mathrm{Hg}^{2+}$ analysis. In this feature article, we review the recent advances in fluorescent probes for $\mathrm{Hg}^{2+}$ analysis, focusing on probe response modes, including signal-decreased fluorescent probes, signal-enhanced fluorescent probes, ratiometric fluorescent probes as well as fluorescent probes for $\mathrm{Hg}^{2+}$ and other species analysis. Moreover, the design strategies, performance and applications of fluorescent probes are summarized in detail. Challenges and prospects for fluorescent probe are proposed, orienting new design strategies and applications expanding.
\end{abstract}

\section{Introduction}

Mercury is one of the most toxic metal pollutants, which seriously pollutes environment and threatens the organism health $[1,2]$. The main sources of mercury pollution include mineral industry production, chemical manufacturing, waste incineration, and fossil fuel combustion [3-5]. In addition, volcanic activity, forest fire, and atmospheric mercury deposition can also lead to mercury pollution. What's worse, mercury pollution cannot be naturally degraded, and it can further cause atmospheric pollution, soil pollution as well as water pollution once exposed into the environment [6-8]. Mercury will accumulate along the food chain and human at the top of food chain suffered the most $[9,10]$. In this feature article, we focus on the research of mercury ions $\left(\mathrm{Hg}^{2+}\right)$, the main form of mercury.

$\mathrm{Hg}^{2+}$ can be transported throughout the organisms with blood circulation once it enters organisms, causing various diseases with severe toxicity. For example, the horrendous Minamata disease is mainly caused by consumption of mercury-contaminated food. Mineral leaching and human activities can cause the $\mathrm{Hg}^{2+}$ content in water to rise, and $\mathrm{Hg}^{2+}$ will accumulate along the food chain. After humans consume contaminated fish and shrimp and other seafood, $\mathrm{Hg}^{2+}$ affects human health seriously. In addition, industrial wastes containing $\mathrm{Hg}^{2+}$ can also accumulate along crops in terrestrial ecosystems. $\mathrm{Hg}^{2+}$ can interact with active species in vivo, and induce severe mercury poisoning after entering the organism. $\mathrm{Hg}^{2+}$ mainly targets the kidney and brain tissue, and induces kidney tissue damage and neurotoxicity [11-13]. The mechanism of mercury poisoning can be elaborated from three aspects: the electrophilic effect of $\mathrm{Hg}^{2+}$, the "calcium overload" effect caused by $\mathrm{Hg}^{2+}$ and the immune damage effect [11-14]. More specifically, $\mathrm{Hg}^{2+}$ has a high affinity towards active groups due to its high electrophilic effect, such as mercapto, amino, carbonyl and carboxyl groups $[15,16]$. These active groups generally play vital roles in the physiological processes. Once reacted with $\mathrm{Hg}^{2+}$, the activity of active groups and the normal physiological processes in vivo will be seriously disturbed. For

\footnotetext{
* Corresponding authors at: Yantai Institute of Coastal Zone Research, Chinese Academy of Sciences, Yantai 264003, China.

E-mail addresses: liangweizhang@yic.ac.cn (L. Zhang), lxchen@yic.ac.cn (L. Chen).
} 
instance, $\mathrm{Hg}^{2+}$ can strongly combine with mercapto groups, which usually acts as the active site to participate in the redox regulation process in vivo. $\mathrm{Hg}^{2+}$ is also prone to attack DNA strands due to the strong electrophilicity, causing DNA strand breaks and inducing the outbreak of reactive oxygen species [17-20]. Calcium overload caused by $\mathrm{Hg}^{2+}$ is another manifestation of mercury poisoning. Calcium ion homeostasis is critical for maintaining normal cell physiological function. Under normal conditions, there is a huge concentration difference between intracellular and extracellular calcium ions. Maintaining such a huge concentration difference requires a series of transport mechanisms. However, $\mathrm{Hg}^{2+}$ interferes with the transport mechanism and induces "calcium overload" effect $[21,22]$. The organism itself has various protective mechanisms to deal with the mercury poisoning [23,24]. Selenium-mercury complexes formed in erythrocyte and plasma belong to first-line protection $[15,16]$. Glutathione (GSH), which can help the organism relief mercury poisoning by combining $\mathrm{Hg}^{2+}$ with the sulfhydryl group, belongs to second-line protection. However, alleviating mercury poisoning by GSH will sacrifice the antioxidant capacity of organism [25-28]. Once $\mathrm{Hg}^{2+}$ concentration far exceeds the regulation ability of organism, $\mathrm{Hg}^{2+}$ will continue to combine with other biologically active molecules and cause severe damages to organism [29-32]. Based on these facts, real-time and online monitoring the concentration fluctuation of $\mathrm{Hg}^{2+}$ in environmental samples and biological samples is crucial to organism health.

Traditional analytical techniques for $\mathrm{Hg}^{2+}$ detection, like spectrophotometry, atomic absorption spectroscopy, atomic fluorescence spectroscopy, x-ray absorption spectroscopy, and inductively coupled plasma mass spectrometry cannot achieve real-time and in situ monitoring at the expense of time-consuming inspection processes, complex sample pretreatment and destruction of biological samples [33-39]. Fluorescence probe technology has good selectivity, high sensitivity, fast response speed and the capability of real-time online detection, thus it has been widely applied for the detection of ions, molecules as well as other species [40-46]. So far, a variety of fluorescent probes for $\mathrm{Hg}^{2+}$ detection have been developed [47-55]. Even though some excellent reviews give the related topic and they focus on the fundamental and design aspects of fluorescent probes for various heavy metal ions [5659]. Only a few specific reviews have summarized the detection methods for $\mathrm{Hg}^{2+}[60,61]$. However, they merely focus on the details of detection, and do not systematically introduce the design strategies, response modes, challenges and prospects of fluorescent probes, which can provide ideas and opinions for the development of novel fluorescent probes. And the design strategies as well as new mechanisms for construction of $\mathrm{Hg}^{2+}$ fluorescent probes have been developed recently. Therefore, specifically review to introduce fluorescent probes for $\mathrm{Hg}^{2+}$ analysis is meaningful. In this article, we will summarize the response types, design strategies, performances and applications of the fluorescent probes for $\mathrm{Hg}^{2+}$ detection. The fluorescent probes are classified according to the changes in fluorescence signals, including signaldecreased fluorescent probes, signal-enhanced fluorescent probes and ratiometric fluorescent probes (Fig. 1). In addition, multi-responsive fluorescent probes that can simultaneously detect $\mathrm{Hg}^{2+}$ and other species are also summarized.

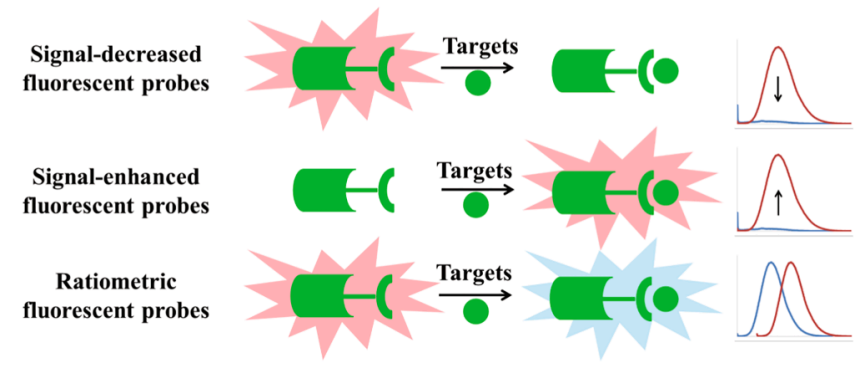

Fig. 1. Typical signal response modes of fluorescent probes.

\section{Signal-decreased fluorescent probes for $\mathrm{Hg}^{2+}$ analysis}

Signal-decreased fluorescent probes are also called on-off type fluorescent probes, namely the fluorescence signals are decreased after reacting with targets. This type of probes is usually applied for $\mathrm{Hg}^{2+}$ and $\mathrm{Cu}^{2+}$ detection. In this section, we will introduce the signal-decreased fluorescent probes rely on different reaction types, including $\mathrm{N}$-atom complexation, deprotection reaction of dithioacetals and $\mathrm{S}$-atom complexation.

\subsection{Fluorescent probes for $\mathrm{Hg}^{2+}$ analysis based on $\mathrm{N}$-atom complexation}

Ono and co-workers reported an oligodeoxyribonucleotide (ODN)based probe 1 for $\mathrm{Hg}^{2+}$ detection in aqueous solutions [62]. Inspired by the strong binding reaction between $\mathrm{Hg}^{2+}$ and thymine-thymine (T-T) base pairs in DNA duplexes, researchers linked ODN with fluorescein fluorophore and dabcyl quencher unit to afford a novel fluorescent probe 1 (Fig. 2). After addition of $\mathrm{Hg}^{2+}$, thymine residues interacted with $\mathrm{Hg}^{2+}$ to form a hairpin structure, accompanied by a decrease in fluorescence signal intensity. Probe 1 showed good selectivity and sensitivity towards $\mathrm{Hg}^{2+}$, and the limit of detection (LOD) of probe 1 can reach $40 \mathrm{nM}$. Later, Wang and co-workers reported a new fluorescent probe 2 for $\mathrm{Hg}^{2+}$ detection based on thymine residue (Fig. 2) [63]. And probe 2 displayed superior selectivity towards $\mathrm{Hg}^{2+}$. Probe 2 showed practicality for $\mathrm{Hg}^{2+}$ detection in solution, and the LOD of probe 2 was $0.1 \mu \mathrm{M}$. Chiang et al. also developed a turn-on fluorescent probe for $\mathrm{Hg}^{2+}$ selective detection based on polythymine oligonucleotide [64]. The probe showed practicality for $\mathrm{Hg}^{2+}$ detection in pond water and batteries, and the LOD of probe was $0.6 \mathrm{ppb}$.

Given pyrene unit displayed high fluorescence quantum yield, Banerjee et al. designed and synthesized a novel probe 3 that consisted of pyrene unit and methionine units for $\mathrm{Hg}^{2+}$ selectively detection [65]. Initially, probe 3 emitted strong fluorescence signal at $455 \mathrm{~nm}$. After reacting with $\mathrm{Hg}^{2+}$, the fluorescence signal from probe 3 was obviously quenched. Probe 3 showed fairly high binding constant towards $\mathrm{Hg}^{2+}$ $\left(7.5630 \times 10^{4}\right)$, and the fluorescence lifetime of the probe as well as its $\mathrm{Hg}^{2+}$-complex were $1.54 \mathrm{~ns}$ and $0.72 \mathrm{~ns}$, respectively. Probe 3 was applied for $\mathrm{Hg}^{2+}$ determination in industrial wastewater successfully.

Vengaian and co-workers reported a fluorescent probe 4 for $\mathrm{Hg}^{2+}$ detection based on phenothiazine-diaminomalenonitrile derivative [66]. They chose phenothiazine derivative as fluorescence reporter and probe 4 was synthesized after connecting diaminomaleonitrile as response site (Fig. 3). The nitrile group with strong electronwithdrawing ability can effectively promote the intramolecular charge transfer process. The fluorescence signal decreased significantly after adding $\mathrm{Hg}^{2+}$, however, the fluorescence signal recovered again after adding $\mathrm{S}^{2-}$. Therefore, researchers proposed the concept of turn-off-on logic gate for $\mathrm{Hg}^{2+}$ and $\mathrm{S}^{2-}$ sensing. Furthermore, the probe exhibited low cell toxicity and was applied for $\mathrm{Hg}^{2+}$ imaging in living cells.
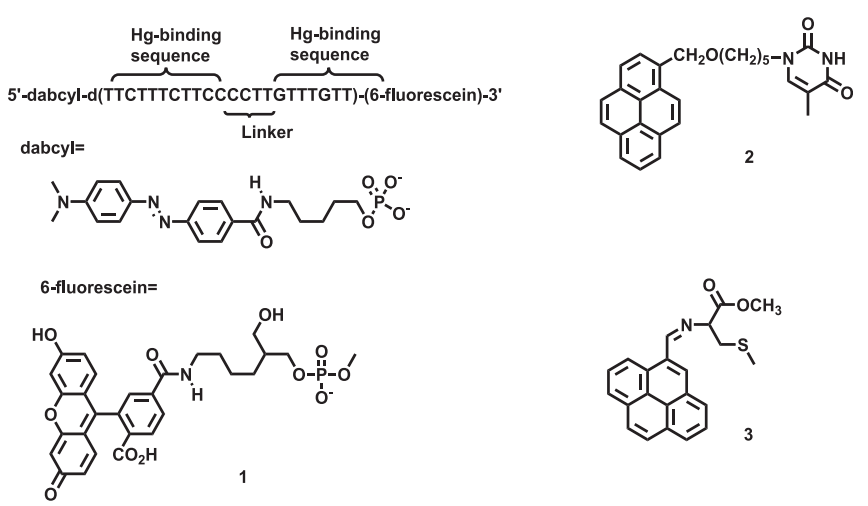

Fig. 2. Structures of 1-3. 
<smiles>CN1c2ccccc2Sc2cc(/C=N/C(C#N)C(=N)N)ccc21</smiles><smiles>Cc1cc2cc3ccccc3cc2cc1N=CC1=C(O)C=CC2C=CC=CC12</smiles>

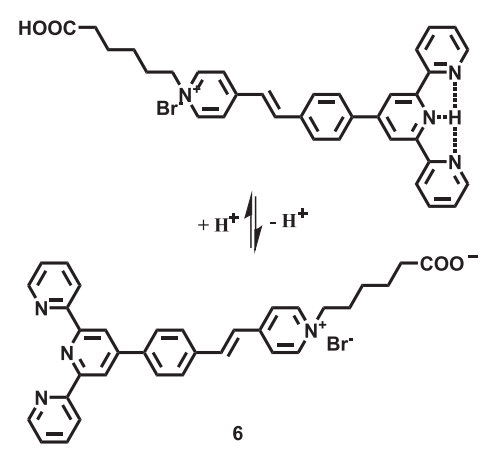

Fig. 3. Structures of 4-6.

Shyamal and co-workers designed a "turn-off" fluorescent probe $\mathbf{5}$ for $\mathrm{Hg}^{2+}$ selective recognition in solution [67]. The probe 5 was synthesized by connecting anthracene with naphthalimide via a Schiff base linker and the introduction of anthracene can increase the hydrophobicity of the probe. Probe $\mathbf{5}$ showed strong fluorescence signal in the binary solvent mixture $\left(\mathrm{THF} / \mathrm{H}_{2} \mathrm{O}, 3: 7, \mathrm{v} / \mathrm{v}\right)$. After reacted with $\mathrm{Hg}^{2+}$, the fluorescence signal decreased apparently. Scanning electron microscope analysis, dynamic light scattering analysis, TRPL analysis and optical microscope were used to study the particles size and growth process during aggregation after reacted with $\mathrm{Hg}^{2+}$ in different mixture. The applications of probe in test strip provided convenience for $\mathrm{Hg}^{2+}$ detection in the actual samples.

Zhou and co-workers reported a terpyridine-based fluorescent probe 6 for $\mathrm{Hg}^{2+}$ sensing [68]. Probe 6 was composed of terpyridine and hexanoic acid units. The probe 6 showed good selectivity for $\mathrm{Hg}^{2+}$ in acidic environment although $\mathrm{Cd}^{2+}$ interfered with the $\mathrm{Hg}^{2+}$ detection in neutral aqueous solution. Since probe 6 was aggregated after reacted with $\mathrm{Hg}^{2+}$, the author introduced a procedure for $\mathrm{Hg}^{2+}$ removal. Furthermore, the probe 6 can be effectively regenerated and recovered after being treated with $\mathrm{H}_{2} \mathrm{~S}$.

\subsection{Fluorescent probes for $\mathrm{Hg}^{2+}$ analysis based on deprotection of dithioacetals}

The deprotection reaction of dithioacetals requires $\mathrm{Hg}^{2+}$. Based on this principle, researchers have designed a series of fluorescent probes for $\mathrm{Hg}^{2+}$ detection (Fig. 4). And the fluorescent probes based on deprotection reaction of dithioacetals undergo chemical reaction under test conditions, thus this type of probes is usually irreversible.

Rani synthesized a signal-decreased fluorescent probe $\mathbf{7}$ for $\mathrm{Hg}^{2+}$ sensing (Fig. 5) [14]. Researchers selected pyrene unit as chromophore for its superior spectral performance and they chose mercaptothiadiazole moiety as the recognition unit for $\mathrm{Hg}^{2+}$ detection. Probe 7 initially emitted fluorescence signals at 378, 388 and $397 \mathrm{~nm}$. After adding $\mathrm{Hg}^{2+}$, the electrons were transferred from the pyrene unit to metal ion $\mathrm{Hg}^{2+}$, which can promote spin-orbit coupling due to the heavy atom effect, and $\mathrm{Hg}^{2+}$ quenched the fluorescence signals of probe 7 . The mechanism of probe 7 for $\mathrm{Hg}^{2+}$ detection was confirmed through DFT analysis. The response of probe 7 towards $\mathrm{Hg}^{2+}$ was reversible, and the combination of probe 7 and $\mathrm{Hg}^{2+}$ can be reversed by cysteine. Probe 7 can be applied for $\mathrm{Hg}^{2+}$ detection in water samples and living cells.

Zhao and co-workers developed a fluorescent probe 8 for $\mathrm{Hg}^{2+}$ visual detection based on aggregation-induced emission [69]. Probe 8 was synthesized based on tetraphenylethylene derivatives. Researchers

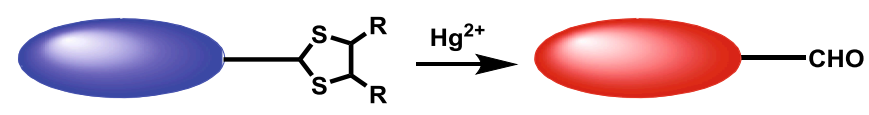

Fig. 4. Summary of strategies for fluorescent probes based on deprotection of dithioacetals.
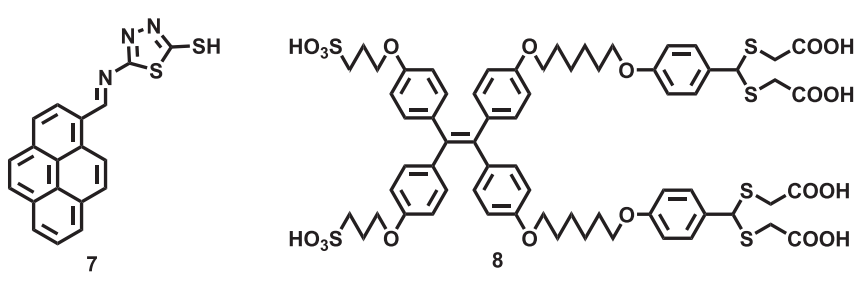

Fig. 5. Structures of 7-8.

introduced sulfonic acid groups to increase the water solubility of probe, and dithioacetal was selected as response sites for $\mathrm{Hg}^{2+}$ detection. Furthermore, fibrous strips were decorated with probe 8 for $\mathrm{Hg}^{2+}$ detection in actual samples. They attached active carboxyl groups to the probe for inducing condensation reaction with the terminal amino groups on the fiber surface, thereby connecting the probe to the fiber surface for $\mathrm{Hg}^{2+}$ sensing. This process was characterized by scanning electron microscope analysis and X-ray photoelectron spectroscope analysis. Probe $\mathbf{8}$ cannot move freely after fixed on the fiber surface, thus probe 8 emitted strong fluorescent signals. After reacting with $\mathrm{Hg}^{2+}$, the fiber mat exhibited a significant decrease in fluorescence signal. The loading device with fluorescent probe $\mathbf{8}$ fixed on the test paper provided convenience for on-line detection compared with the $\mathrm{Hg}^{2+}$ detection in solutions.

\subsection{Fluorescent probes for $\mathrm{Hg}^{2+}$ analysis based on $\mathrm{S}$-atom complexation}

Based on $\mathrm{Hg}^{2+}$ has strong sulfur affinity, researchers constructed a series of fluorescent probes by adopting $S$ atom, azathiocrown ether and thioether-rich crown as response unit to achieve $\mathrm{Hg}^{2+}$ analysis (Fig. 6).

To overcome the poor water solubility of fluorescent probes, Descalzo and co-workers constructed a fluorescent probe 9 for $\mathrm{Hg}^{2+}$ detection (Fig. 7) [70]. They used the phenoxazinone unit as fluorophore to guarantee sufficient water solubility, and phenoxazinone can emit intense fluorescence signals in the visible spectral region. In order to improve the selectivity of probes for $\mathrm{Hg}^{2+}$ detection, researchers chose dithia-dioxa-monoaza crown unit as the response group. The fluorescence signals were reduced after reacted with $\mathrm{Hg}^{2+}$, and probe 9 exhibited high selectivity for $\mathrm{Hg}^{2+}$ with a LOD of $10^{-7} \mathrm{M}$ in solution.

Koteeswari and co-workers reported a series of fluorescent probes 10a-e based on acridinedione derivatives linked with amidothiourea for $\mathrm{Hg}^{2+}$ detection [71]. Probes can be excited by one-photon and twophoton microscope for $\mathrm{Hg}^{2+}$ analysis. Probe 10a showed a 92-fold fluorescence quenching after reacted with $\mathrm{Hg}^{2+}$, and it can be
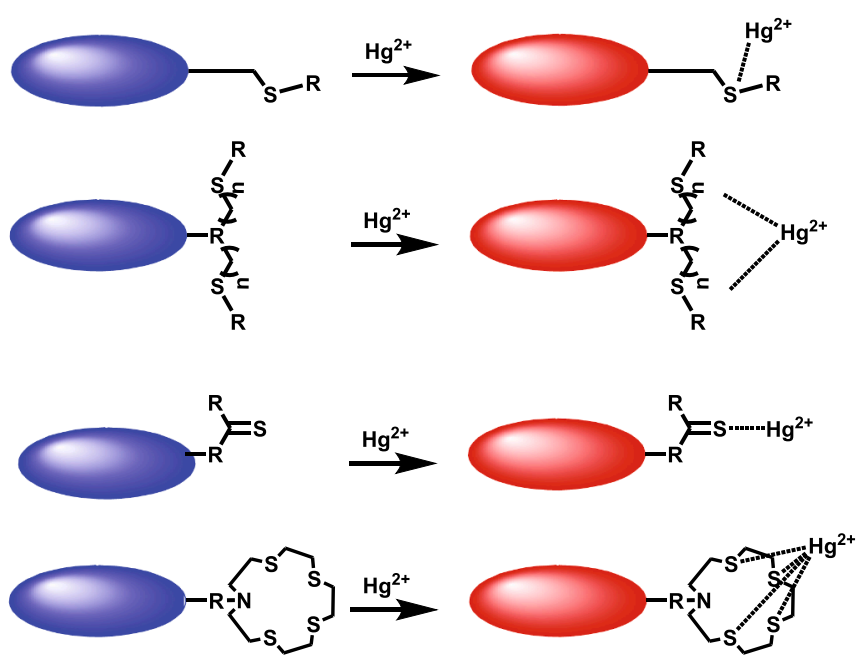

Fig. 6. Summary of strategies for fluorescent probes based on S-atom complexation. 


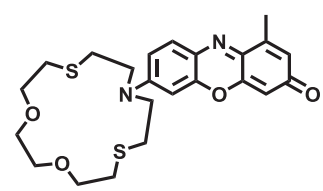

9

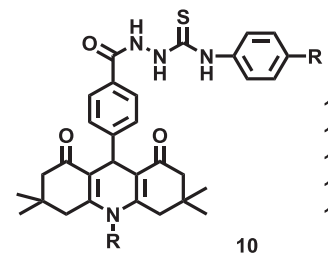

10a: $R=-H, X=-H$ 10b: $\mathrm{R}=-\mathrm{H}, \mathrm{X}=-\mathrm{OCH}_{3}$ $10 \mathrm{c}: \mathrm{R}=-\mathrm{H}, \mathrm{X}=-\mathrm{NO}_{2}$ 10d: $\mathrm{R}-\mathrm{CH}_{3}, \mathrm{X}=-\mathrm{H}$ $10 \mathrm{e}: R=-p$ totyl, $X=-H$

Fig. 7. Structures of 9-10.

employed for $\mathrm{Hg}^{2+}$ rapid detection in cells with a LOD of $2 \mathrm{nM}$.

For $\mathrm{Hg}^{2+}$ fluorescent probes with fluorescence signal decrease, researchers should pay attention to the false positives experimental results that fluorescence quenching caused by external environmental factors when applying this type of probes for analysis. In addition, the high background signals from probes limit the improvement of probe sensitivity, which poses a great challenge for low-level targets detection. Thus, these limitations of this type of probes in analysis field should be improved.

\section{Signal-enhanced fluorescent probes for $\mathrm{Hg}^{2+}$ analysis}

$\mathrm{Hg}^{2+}$ is usually considered as a fluorescence quencher which can reduce fluorescence signal output. Therefore, it is valuable to obtain signal-enhanced fluorescent probes. The signal-enhanced fluorescent probes can be called off-on type fluorescent probes, and the fluorescence signals from which are increased after reacting with analytes. The initial fluorescence signal values from the signal-enhanced fluorescent probes are low, that is, the background signals are low. After reacting with analytes, the fluorescence signals from probes are significantly enhanced. Compared with the signal-decreased fluorescent probes, the signal-enhanced fluorescent probes have higher sensitivity and are more suitable for qualitative analysis. In this section, we will introduce the signal-enhanced fluorescent probes according to different reaction mechanisms: rhodamine ring-opening reaction, deprotection reaction of dithioacetals, $\mathrm{S}$-atom complexation and $\mathrm{N}$-atom complexation.

\subsection{Fluorescent probes for $\mathrm{Hg}^{2+}$ analysis based on rhodamine ring- opening reaction}

$\mathrm{Hg}^{2+}$ has strong sulfur affinity, and the reactions based on $\mathrm{Hg}^{2+}$. promoted desulfurization reactions, including ring-opening and elimination reaction of the rhodamine structure, cyclization as well as hydrolysis, are employed to construct fluorescent probes for $\mathrm{Hg}^{2+}$ detection [71]. Rhodamine dyes have been widely used in the field of biological imaging due to its high molar absorption coefficient, superior fluorescence quantum yield as well as long emission wavelength. Generally, rhodamine dyes in the form of spirolactam rings have no fluorescent signals. After reacting with the targets, the spirolactam ring opens accompanied by emitting strong fluorescent signals from rhodamine dyes. So far, the $\mathrm{Hg}^{2+}$ fluorescent probes designed based on the rhodamine skeleton have two main mechanisms: 1) $\mathrm{Hg}^{2+}$ promotes cyclization by desulfurization, in which process the carbonyl group of spirolactam acts as reaction site, leading to ring opening; 2) The coordination between $\mathrm{Hg}^{2+}$ and receptors, in which process the carbonyl group of spirolactam plays a complexing role, leading to ring opening [72]. In the first case, the ring-opening reaction of rhodamine is irreversible because it produces a new molecule. In the latter case, the ringopening reaction of rhodamine is reversible because it is based on $\mathrm{Hg}^{2+}$ complexes.

Given the strong thiophilic affinity of $\mathrm{Hg}^{2+}$, Tae group coupled the rhodamine cyclization process with $\mathrm{Hg}^{2+}$-promoted reaction of thiosemicarbazides to design a novel probe 11 for $\mathrm{Hg}^{2+}$ detection (Fig. 8) [73]. Originally, probe existed in the spirocyclic form. After adding $\mathrm{Hg}^{2+}$, it would promote thiosemicarbazides to form 1,3,4-oxadiazoles accompanied by emitting strong yellow fluorescence signals. This

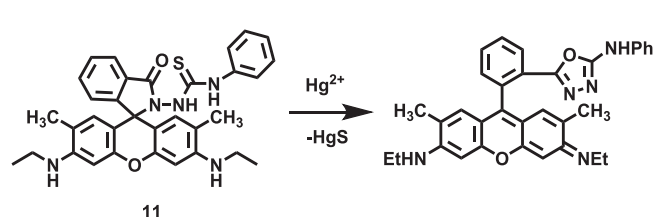

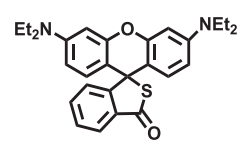

12

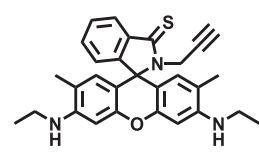

13
11

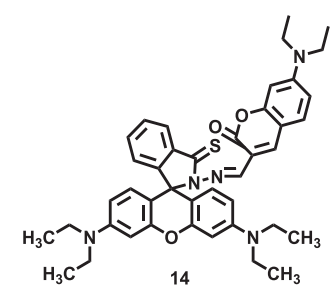

Fig. 8. Structures of 11-14. reaction did not require high temperature and it can be conducted at room temperature in a 1:1 stoichiometric manner for $\mathrm{Hg}^{2+}$ detection, in addition, the LOD of probe 11 for $\mathrm{Hg}^{2+}$ analysis was below $2 \mathrm{ppb}$. Later, the same group applied probe $\mathbf{1 1}$ for $\mathrm{Hg}^{2+}$ imaging analysis in vivo for the first time [74]. They investigated the selectivity, reaction kinetics and $\mathrm{pH}$ application range of the probe, and the results demonstrated that probe 11 was suitable for $\mathrm{Hg}^{2+}$ detection in vivo. Probe 11 can achieve $\mathrm{Hg}^{2+}$ selective detection within $1 \mathrm{~min}$, and it was stable in the $\mathrm{pH}$ range of 4-14. Probe 11 was successfully applied for $\mathrm{Hg}^{2+}$ detection in cells, organs and zebrafish, and the experimental results of $\mathrm{Hg}^{2+}$ detection in vertebrate zebrafish exhibited the potential application of probe in vivo. They pioneered the application of fluorescent probe to in vivo analysis.

After replacing the nitrogen atom in rhodamine spironolactone with sulfur atom, Zhan and co-workers obtained a monothiospirolactonebased rhodamine derivative 12, which had better pH stability [75]. After replacement, the thiol atom can be served as an active site for $\mathrm{Hg}^{2+}$ detection, and probe 12 was stable in the $\mathrm{pH}$ range of $1-11$. The reaction between probe 12 and $\mathrm{Hg}^{2+}$ was reversible, and the $\mathrm{Hg}^{2+}$ detection by probe 12 can be naked-eye observed in the solution.

Lin group reported a turn-on fluorescent probe 13 for $\mathrm{Hg}^{2+}$ detection by a novel sensing strategy. Probe $\mathbf{1 3}$ consisted of a rhodamine reporter unit, an alkyne unit, and an $S$ atom response site [76]. Alkyne unit and $S$ atom were selected as response sites due to the thiophilic and $\pi$-philic nature of $\mathrm{Hg}^{2+}$. Probe 13 in spirocyclic form had no fluorescence signal, and it would convert into an open-ring product with strong fluorescence signal after reacted with $\mathrm{Hg}^{2+}$. The probe can selectively respond to $\mathrm{Hg}^{2+}$ within $3 \mathrm{~min}$ without interference from other species. Probe 13 was cell membrane permeable and it can be used for intracellular $\mathrm{Hg}^{2+}$ detection with a LOD of $39 \mathrm{nM}$. The new design strategy can be used for constructing novel fluorescent probes for targets detection.

Based on rhodamine ring-opening reaction, Ma and co-workers reported a turn-on fluorescent probe 14 for $\mathrm{Hg}^{2+}$ selective detection [77]. Probe 14 consisted of rhodamine and coumarin dyes, and the LOD of probe 14 can reach $4.0 \times 10^{-8} \mathrm{M}$. The fluorescence signals of probe 14 was significantly enhanced about 24-fold after reacted with $\mathrm{Hg}^{2+}$ in $50 \%$ water/ethanol buffer ( $\mathrm{pH} 7.4$ ), in addition, probe 14 and $\mathrm{Hg}^{2+}$ can form a 1: 1 complex. The fluorescence response of probe 14 towards $\mathrm{Hg}^{2+}$ was reversible, and the probe can be utilized for $\mathrm{Hg}^{2+}$ detection in actual samples including tap water and river water.

Mandal and co-workers also reported a signal-enhanced fluorescent probe $\mathbf{1 5}$ for $\mathrm{Hg}^{2+}$ detection based on rhodamine ring-opening mechanism (Fig. 9) [78]. Rhodamine dye was selected as fluorescence reporter, and a new probe 15 was obtained for $\mathrm{Hg}^{2+}$ sensing after being linked to thiophene. The synthesis procedure of the probe was simple, and the structure of probe 15 was characterized by ${ }^{1} \mathrm{H}$ NMR, mass spectra as well as FTIR, and the purity of the probe was detected by elemental analysis. After reacted with $\mathrm{Hg}^{2+}$, the fluorescence signals from probe $\mathbf{1 5}$ were enhanced significantly and the naked-eye color of probe 15 changed from colorless to red. The LOD of probe $\mathbf{1 5}$ was as low as $1.0 \times 10^{-9} \mathrm{M}$, and the probe can be applied for $\mathrm{Hg}^{2+}$ detection in allamanda puberula, 


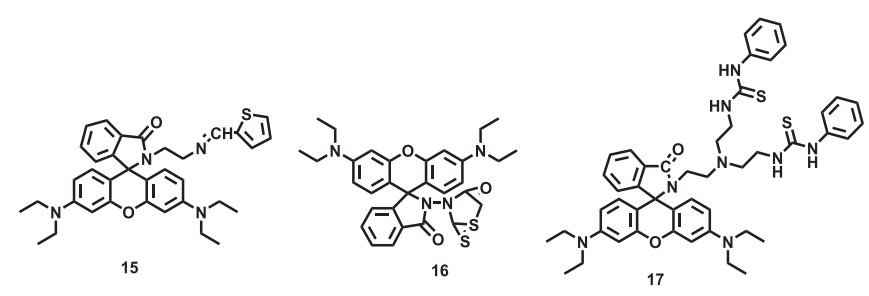

Fig. 9. Structures of 15-17.

candida albicans and cells.

Bera and co-workers reported a turn-on fluorescent probe $\mathbf{1 6}$ for $\mathrm{Hg}^{2+}$ selective detection [79]. They selected rhodamine as fluorophore and introduced 3-aminorhodanine receptor to increase the affinity of probe towards $\mathrm{Hg}^{2+}$. After reacted with $\mathrm{Hg}^{2+}$, probe 16 in benzenoid form converted to quininoid form with increased fluorescence signals. The reaction between probe $\mathbf{1 6}$ and $\mathrm{Hg}^{2+}$ was irreversible, and probe can be applied in a wide $\mathrm{pH}$ range (pH 5-10). Probe 16 can react with $\mathrm{Hg}^{2+}$ quickly within $3 \mathrm{~min}$ and it can be applied for $\mathrm{Hg}^{2+}$ detection at nanomolar level. Researchers applied probe $\mathbf{1 6}$ for $\mathrm{Hg}^{2+}$ detection in living cells and zebrafish, and time evolution of inorganic mercury distribution in zebrafish can be obtained using the probe 16. However, the detection of $\mathrm{Hg}^{2+}$ by probe $\mathbf{1 6}$ was hindered in pure acetonitrile medium.

To improve the binding capacity of fluorescent probe towards $\mathrm{Hg}^{2+}$, Hong and co-workers introduced a phenyl isothiocyanate unit into the rhodamine fluorophore to afforded probe 17 [80]. After addition of $\mathrm{Hg}^{2+}$, probe 17 strongly complexed with sulfur atoms and a desulfurization reaction occurred simultaneously that further resulted in the ring opening of rhodamine spirolactam. The stoichiometry of probe and $\mathrm{Hg}^{2+}$ was $1: 2$, and the binding constant was $2.89 \times 10^{8} \mathrm{M}^{-2}$. After probe 17 reacted with $\mathrm{Hg}^{2+}, \mathrm{Hg}^{2+}$ induced an intramolecular charge transfer process accompanied by the turning on of fluorescence. The new sensing mechanism proposed by Hong et al. was confirmed by LC-MS spectra, IR spectra and ${ }^{1} \mathrm{H}$ NMR spectra. The probe exhibited good selectivity and binding capacity for $\mathrm{Hg}^{2+}$, and it can be applied for $\mathrm{Hg}^{2+}$ detection in cells. In addition, the probe-containing cellulose disc produced by researchers can be applied for $\mathrm{Hg}^{2+}$ determination via naked eye, which revealed the promising prospect of probe $\mathbf{1 7}$ in the portable onsite detection of $\mathrm{Hg}^{2+}$.

Based on ring-opening reaction of rhodamine, $\mathrm{Hu}$ and co-workers reported a reversible fluorescent probe $\mathbf{1 8}$ for $\mathrm{Hg}^{2+}$ selective detection (Fig. 10) [72]. After adding $\mathrm{Hg}^{2+}$, the fluorescent signals from probe 18 were increased approximately 105 times. The binding and dissociation constants of probe 18 for $\mathrm{Hg}^{2+}$ were $0.22 \times 10^{5} \mathrm{M}^{-1}$ and $25.2 \mu \mathrm{M}$ respectively, and the binding stoichiometry was $1: 1$. Using $\mathrm{S}^{2-}$ and $\mathrm{I}^{-}$,
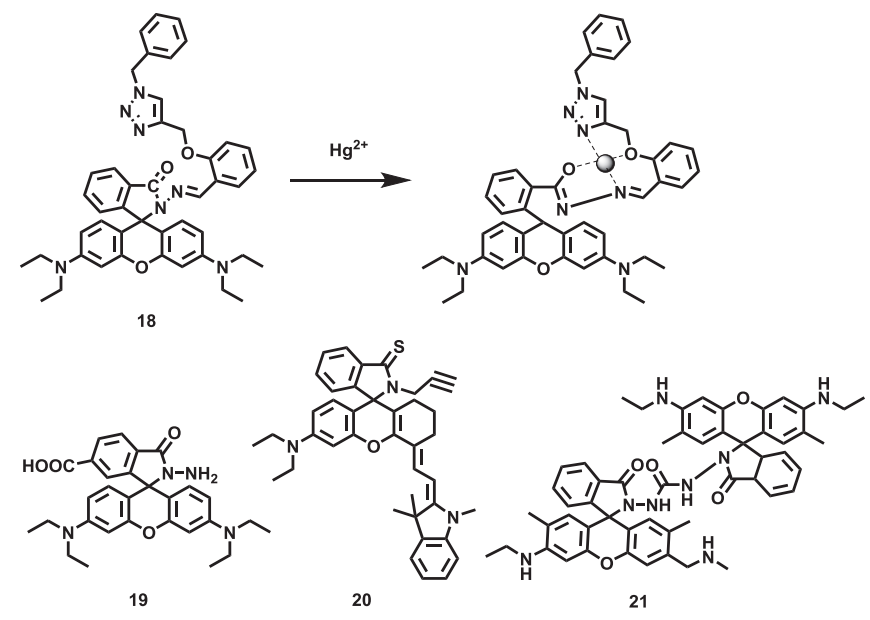

Fig. 10. Structures of 18-21. researchers showed a new idea of reversible logic gates based on the reversible $\mathrm{Hg}^{2+}$ recognition. In addition, probe 18 can be utilized for $\mathrm{Hg}^{2+}$ detection in actual samples of lake and rain water, and it can be employed for intracellular $\mathrm{Hg}^{2+}$ imaging.

$\mathrm{Li}$ and co-workers reported a turn-on fluorescent probe 19 for $\mathrm{Hg}^{2+}$ detection based on irreversible ring-opening reaction of rhodamine [81]. To improve the water solubility of probe, researchers introduced a hydrophilic carboxylic acid unit into the probe structure. After the addition of 1 equiv. $\mathrm{Hg}^{2+}$, a 42 -fold increase in fluorescence signal can be observed within $3 \mathrm{~min}$. Probe 19 showed good spectral performances for $\mathrm{Hg}^{2+}$ analysis, and it can be adopted for $\mathrm{Hg}^{2+}$ selective detection in actual water samples as well as living cells.

Considering that the near-infrared fluorescence signal has unique advantages in biological imaging, including less light damage to tissues and deep penetration depth, Wang and co-workers designed a nearinfrared fluorescent probe $\mathbf{2 0}$ for $\mathrm{Hg}^{2+}$ detection [82]. Researchers connected semi-cyanine with rhodamine to obtain a fluorescent reporter with a larger conjugated system, which emitted near-infrared fluorescence signal at $760 \mathrm{~nm}$. After the fluorescent reporter reacted with prop2-yn-1-amine, probe $\mathbf{2 0}$ was synthesized. The ring-opening reaction of rhodamine caused by $\mathrm{Hg}^{2+}$ occurred and the fluorescence signal at 760 $\mathrm{nm}$ was significantly enhanced once addition of $\mathrm{Hg}^{2+}$. The reaction mechanism of probe 20 was confirmed by ${ }^{1} \mathrm{H}$ NMR analysis, DFT analysis and MS analysis. In addition, probe 20 can be applied for $\mathrm{Hg}^{2+}$ imaging in living cells and mice owing to the near-infrared fluorescence signals from probe $\mathbf{2 0}$.

Based on rhodamine ring-opening mechanism, Yang and co-workers developed a turn-on fluorescent probe $\mathbf{2 1}$ for $\mathrm{Hg}^{2+}$ selective sensing [83]. Probe $\mathbf{2 1}$ was composed of a rhodamine dimer, and probe $\mathbf{2 1}$ in the spirocyclic form had no fluorescent signal. After reacting with $\mathrm{Hg}^{2+}$, rhodamine structure in probe $\mathbf{2 1}$ turned to the ring-opened form and engendered a 478 -fold fluorescent signal enhancement at $561 \mathrm{~nm}$. The sensing mechanism was verified by IR spectra and ${ }^{1} \mathrm{H}$ NMR titration analysis. The stoichiometry between probe 21 and $\mathrm{Hg}^{2+}$ was $1: 2$, and the LOD of probe 21 can reach $1.3 \mathrm{ppb}$. Furthermore, probe 21 can be employed for $\mathrm{Hg}^{2+}$ imaging in living cells and tissues.

Fluorescent probes based on rhodamine ring-opening reaction are usually complex with $\mathrm{Hg}^{2+}$ using $\mathrm{N}$ atom. Other groups, for instance carbonyl, alkynyl and $\mathrm{S}$ atom can promote rhodamine ring-opening reaction. Whether the ring-opening reaction is reversible needs to be analyzed according to the actual situation.

\subsection{Fluorescent probes for $\mathrm{Hg}^{2+}$ analysis based on deprotection of dithioacetals}

$\mathrm{Hg}^{2+}$-induced conversion of 1,3-dithiane to carbaldehyde is an efficient umpolung reaction, which can favor the formation of intramolecular charge transfer (ICT) mechanism in compounds. Based on this principle, Guo group reported a turn-on fluorescent probe 22 for $\mathrm{Hg}^{2+}$ selective detection based on benzoxadiazole derived dithiane (Fig. 11) [84]. After addition of $\mathrm{Hg}^{2+}$, an aldehyde recovery reaction occurred, accompanied by an increase in the fluorescent signal. Probe 22 was nonfluorescence because of the weak electron withdrawing ability of 7$\left(1^{\prime}, 3^{\prime}\right.$-dithiane). After $\mathrm{Hg}^{2+}$-triggered aldehyde recovery reaction occurred, the strong electron-withdrawing properties of 7-aldehyde were conducive to the ICT effect of the product and induced strong fluorescence emission. The fluorescence signals can reach equilibrium quickly within $3 \mathrm{~min}$, and probe 22 can be utilized for detecting $\mathrm{Hg}^{2+}$ in zebrafish.

The determination of total mercury content was readily and can be done by specific techniques. However, detection of different forms of mercury poses a huge challenge to existing analysis techniques, for example, detection of $\mathrm{MeHg}^{+}$and $\mathrm{Hg}^{2+}$ separately. Based on covalentassembly, Zhang and co-workers achieved differentiated detection of $\mathrm{Hg}^{2+}$ and $\mathrm{MeHg}^{+}$in solution by multiplexing in the time domain with a single fluorescent probe 23 [85]. For $\mathrm{MeHg}^{+}$and $\mathrm{Hg}^{2+}$ separate 
<smiles>CC[C@@H]1[C@@H](C)C[C@H]1C</smiles><smiles>CC(=O)CN(C)c1ccc(C2SCCS2)c(-c2ccccc2N)c1</smiles>

23<smiles>CCN(CC)c1ccc2cc(C3SC(C(=O)O)C(C(=O)O)S3)c(=O)oc2c1</smiles>

25a

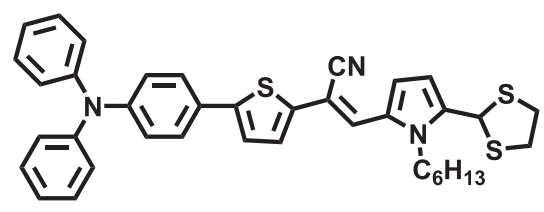

24

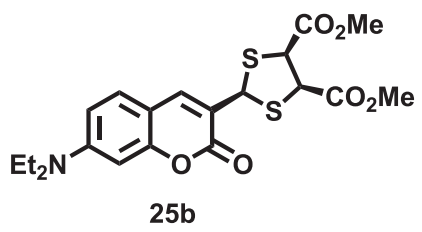

Fig. 11. Structures of 22-25.

detection, there were several considerations: a) the probe should have appropriate reaction kinetics for $\mathrm{Hg}^{2+}$ detection, not only to achieve the purpose of distinguishing monitoring, but also to complete the measurement within a reasonable time range; b) the probe should be applicable in aqueous solutions. Based on these considerations, they designed and synthesized a desirable probe $\mathbf{2 3}$, in which the 2-aminophenyl group can promote the detection of $\mathrm{Hg}^{2+}$, and the methyl ester unit can increase the water solubility of probe. After addition of $\mathrm{Hg}^{2+}$, 1,3-dithiolane was desulfurized to form a formyl unit, which then underwent a condensation reaction with nearby amino groups $\left(-\mathrm{NH}_{2}\right)$ to form phenanthridine. The polycyclic aromatic hydrocarbon had a greater degree of binding than the biphenyl precursor. They proved that $\mathrm{Hg}^{2+}$ and $\mathrm{MeHg}^{+}$can be detected separately by a single kinetic curve through experiments, and the LOD can reach $4.6 \mathrm{pM}$ and $160 \mathrm{pM}$ for $\mathrm{Hg}^{2+}$ and $\mathrm{MeHg}^{+}$respectively. The strategy researchers proposed may be applicable to the differential detection of other substrate pairs, such as cysteine and homocysteine.

Based on the deprotection of dithioacetal induced by $\mathrm{Hg}^{2+}$, Ding and co-workers reported a turn-on fluorescent probe $24 \mathrm{for}^{\mathrm{H}}{ }^{2+}$ selectively detection [2]. Probe $\mathbf{2 4}$ was synthesized through Wittig reaction, Suzuki coupling reaction and Knoevenagel condensation reaction. Cyano group was introduced to decrease the electron transition energy from the ground state to excited state, and it was favor to the intramolecular charge transfer process. FTIR analysis and ${ }^{1} \mathrm{H}$ NMR analysis were conducted to confirm the sensing mechanism of $\mathrm{Hg}^{2+}$-induced deprotection reaction. The LOD of probe 24 for $\mathrm{Hg}^{2+}$ was as low as $8 \times 10^{-7} \mathrm{M}$ and the probe showed powerful imaging potential in test strips detection and cell imaging.

Similarly, Song and co-workers reported two fluorescent probes 25a and $25 \mathrm{~b}$ based on the deprotection of dithioacetal for $\mathrm{Hg}^{2+}$ sensing [86]. 7-N-diethyl coumarin was selected as fluorescence reporter and 2, 3dimercaptosuccinic acid was chosen as recognition unit, the two components were connected by a dithioacetal linker. After reacted with $\mathrm{Hg}^{2+}$, strong fluorescence emission at $502 \mathrm{~nm}$ can be observed. However, the detection for $\mathrm{Hg}^{2+}$ was disturbed by $\mathrm{Ag}^{+}$and $\mathrm{Au}^{+}$. Even so, researchers provided a concept of fluorescent theranostic agent for $\mathrm{Hg}^{2+}$ detection and detoxification treatment based on the deprotection of dithioacetal, which was deserved further exploration.

\subsection{Fluorescent probes for $\mathrm{Hg}^{2+}$ analysis based on S-atom complexation}

Hennrich et al. designed and synthesized a redox switchable fluorescent probe system 26 for $\mathrm{Hg}^{2+}$, detection (Fig. 12) [87]. Interestingly, the two compounds exhibited different cation selectivities. 26a (oxidized form of probe 26) showed good selectivity for $\mathrm{Hg}^{2+}$ with chelation-enhanced fluorescence signal, and $\mathbf{2 6 b}$ (reduced form of probe 26) exhibited spectral response mainly to $\mathrm{Cd}^{2+}$ and $\mathrm{Zn}^{2+}$. Probe 26a can achieve $\mathrm{Hg}^{2+}$ selective analysis with turn-on fluorescence signals in a wide concentration range.

Lippard group reported a novel fluorescent probe 27 for $\mathrm{Hg}^{2+}$ detection with satisfactory water compatibility [88]. They chose seminaphthofluorescein as a fluorescence reporter, and thioether-rich metalbinding unit as a response site. Probe 27 can be used for $\mathrm{Hg}^{2+}$ reversible detection with a LOD of $50 \mathrm{nM}$, and it can also be employed for $\mathrm{Hg}^{2+}$ detection in natural water samples.

To improve the hydrophilicity of fluorescent probe, li and co-workers introduced hydrophilic amino acids dansyl-L-tryptophan methyl ester and constructed a signal-enhanced fluorescent probe 28 for $\mathrm{Hg}^{2+}$ selective detection [89]. Initially, probe $\mathbf{2 8}$ showed weak fluorescence emission peak at $550 \mathrm{~nm}$; upon addition of $\mathrm{Hg}^{2+}$, a strong fluorescence signal enhancement appeared at $487 \mathrm{~nm}$ with the solution color changed from red to green. Probe 28 displayed a low LOD of $5 \mathrm{nM}$ for $\mathrm{Hg}^{2+}$, and the probe had been successfully applied for $\mathrm{Hg}^{2+}$ detection in living cells, which exhibited the potential in biological applications.

$\mathrm{Xu}$ and co-workers designed and synthesized a signal-enhanced fluorescent probe 29 for $\mathrm{Hg}^{2+}$ detection based on desulfurization and cyclization reaction induced by $\mathrm{Hg}^{2+}$ (Fig. 13) [90]. After reacting with $\mathrm{Hg}^{2+}$, the fluorescence signal from probe 29 was significantly enhanced, accompanied by an increase in quantum yield from 0.05 to $0.37 . \mathrm{Hg}^{2+}$ can induce more efficient intramolecular charge transfer from the electron-donating diethylamino group to the electron-withdrawing 1,3,4-oxadiazole group. Probe 29 can achieve $\mathrm{Hg}^{2+}$ selective detection with desirable spectral performance in solution, mammalian cells and bacteria.

Duan and co-workers developed a far-red fluorescent probe $\mathbf{3 0}$ for $\mathrm{Hg}^{2+}$ sensing [91]. Researchers selected seminaphthorhodafluor dye as fluorescence reporter based on its superior spectral performance, and carbonothioate unit was selected as the recognition site. $\mathrm{Hg}^{2+}$ can promote the desulfurization of carbonothioate unit and probe was hydrolyzed to release oxygen anions, which caused the intramolecular charge transfer and emitted strong fluorescence at $625 \mathrm{~nm}$ with a large Stokes shift of $105 \mathrm{~nm}$. Furthermore, probe $\mathbf{3 0}$ with a LOD of $3.6 \mathrm{nM}$ can be applied for $\mathrm{Hg}^{2+}$ recognition in real water samples and living cells.

In order to improve the water solubility of fluorescent probe, Haldar
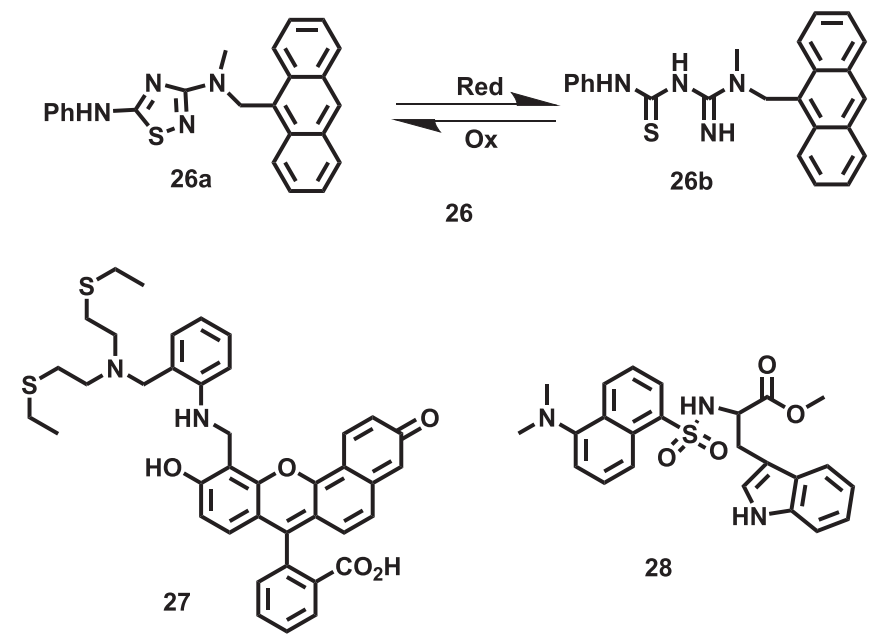

28

Fig. 12. Structures of 26-28. 


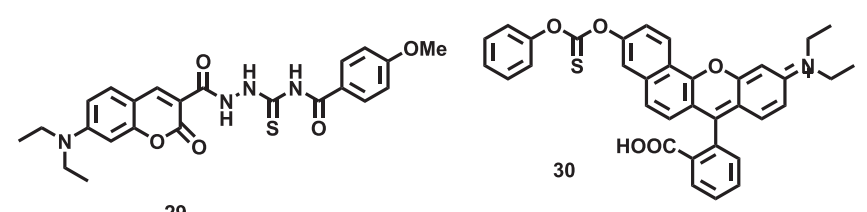

29

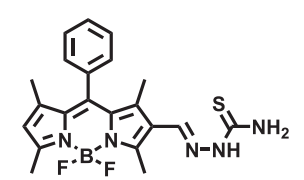

$31 \mathrm{a}$
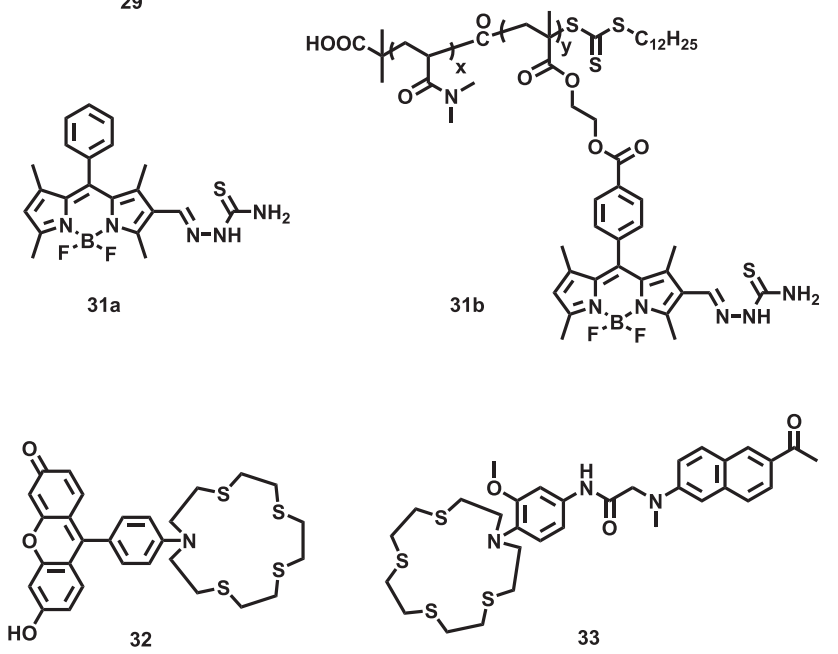

Fig. 13. Structures of 29-33.

and co-workers developed probe 31a based on the BODIPY fluorophore and thiosemicarbazide was introduced as response group [92]. Probe 31a had no fluorescence emission due to the non-radiative inactivation process of the excited state caused by $\mathrm{C}=\mathrm{N}$ isomerization. After reacted with $\mathrm{Hg}^{2+}$, the $\mathrm{C}=\mathrm{N}$ isomerization in the probe was blocked, and probe 31a emitted bright fluorescent signal. However, the hydrolytic stability of the probe was disappointing. Thus to overcome this problem, researchers integrated the BODIPY fluorophore and semicarbazone units into the backbone of the water-soluble polymer N,N'-Dimethylacrylamide. After reacting with thiourea, the desired polymer probe $\mathbf{3 1 b}$ was obtained. Compared with the small molecule probe 31a, the polymer probe 31b showed excellent hydrolytic stability. 31b can test and remove highly toxic $\mathrm{Hg}^{2+}$ from other potential competing metal ions by precipitation (86\%), which expanded the application range of $\mathbf{3 1 b}$ in the field of environmental remediation and pollution control.

Later, Yoon and co-workers designed and synthesized a fluorescent probe 32 for $\mathrm{Hg}^{2+}$ selective detection [93]. The probe contained a fluorescein reporter with desirable water solubility and a thioether-rich crown response unit for $\mathrm{Hg}^{2+}$ recognition. After reacted with $\mathrm{Hg}^{2+}$, there was a 170 -fold increase in fluorescence intensity, and probe $\mathbf{3 2}$ can be applied for $\mathrm{Hg}^{2+}$ detection in fish within the safe edible limit.

Two-photon microscopy using two near infrared photons as excitation source has great advantages of longer observation time, deeper penetration depth and less light tissue damage. Given the advantages of two-photon fluorescent probe, Lim and co-workers reported a novel twophoton fluorescent probe $\mathbf{3 3}$ for $\mathrm{Hg}^{2+}$ selectively detection [94]. They used 6-dimethylamino-2-acetylnaphthalene as a fluorescence reporter and azathiocrown ether as the response site. The probe showed a large two photon action cross section of $110 \mathrm{GM}$ at $780 \mathrm{~nm}$, and it can respond to $\mathrm{Hg}^{2+}$ selectively with a dissociation constant of $0.45 \pm 0.01 \mu \mathrm{M}$. Furthermore, the probe can be applied for $\mathrm{Hg}^{2+}$ detection using twophoton microscopy in living cells and organs at 80-150 $\mu \mathrm{m}$ depth.

\subsection{Fluorescent probes for $\mathrm{Hg}^{2+}$ analysis based on $\mathrm{N}$-atom complexation}

Srivastava and co-workers reported a turn-on fluorescent probe 34 for $\mathrm{Hg}^{2+}$ selective detection based on photoinduced electron transfer mechanism (Fig. 14) [95]. They used anthracene core as the fluorescence signal reporter and two benzhydryl moieties were incorporated
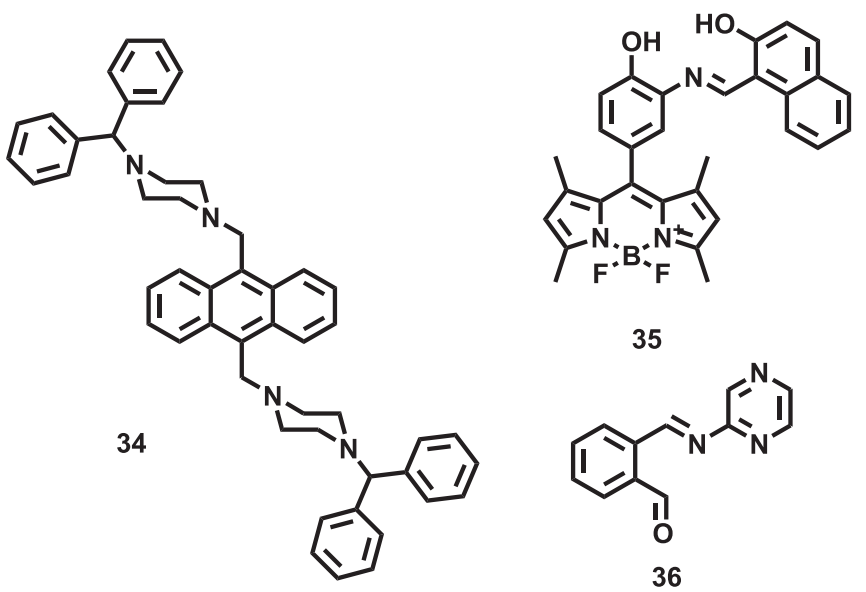

Fig. 14. Structures of 34-36.

into the anthracene core through piperazine bridge units for $\mathrm{Hg}^{2+}$ detection. An obvious fluorescence enhance (10 times) can be observed after addition of $\mathrm{Hg}^{2+}$, and probe 34 can be used for $\mathrm{Hg}^{2+}$ reversible detection in ACN- $\mathrm{H}_{2} \mathrm{O}$ and HEPES buffer. The stoichiometry of probe towards $\mathrm{Hg}^{2+}$ was $1: 2$, and the detection limit was $2 \mathrm{ppb}$. They further applied probe 34 for $\mathrm{Hg}^{2+}$ detection in actual mercury-contaminated water samples, cellulose paper tape, protein medium (such as BSA) and living cells. Furthermore, they utilized probe $\mathbf{3 4}$ for producing a reusable combinational logic circuit. Regrettably, the detection for $\mathrm{Hg}^{2+}$ can be disturbed by $\mathrm{PO}_{4}^{3-}$.

Xiao and co-workers reported a turn-on fluorescent probe $\mathbf{3 5}$ based on BODIPY fluorophore [96]. The probe showed a strong binding capacity for $\mathrm{Hg}^{2+}$, and the association constant was determined to be 9.43 $\times 10^{4} \mathrm{M}^{-1}$. The probe also displayed good imaging capabilities in living cells, zebrafish and nude mouse with LOD of $1.73 \mathrm{nM}$. Unfortunately, $\mathrm{Al}^{3+}$ caused slight interference with $\mathrm{Hg}^{2+}$ detection.

Gangatharan and co-workers reported a fluorescent probe $\mathbf{3 6}$ for $\mathrm{Hg}^{2+}$ sensing based on N-atom complexation reaction [97]. Probe 36 was synthesized from 2-amino pyrazine and phthalaldehyde, and it achieved $\mathrm{Hg}^{2+}$ detection by chelation-induced fluorescence signal changes with a stoichiometry of $1: 1$. After adding $\mathrm{Hg}^{2+}$, probe 36 formed a stable chelate complex with $\mathrm{Hg}^{2+}$, which had a larger conjugated structure. $\mathrm{Hg}^{2+}$ limited the $\mathrm{C}=\mathrm{N}$ isomerization of probe 36 , thereby the fluorescence signal of probe 36 at $437 \mathrm{~nm}$ was enhanced. Based on molecular logic circuits, researchers applied the probe to molecular-level sequential logic gates containing a memory function. Furthermore, researchers produced test kits using probe $\mathbf{3 6}$ for actual samples detection.

\subsection{Fluorescent probes for $\mathrm{Hg}^{2+}$ analysis based on other mechanism}

Fluorescent probes can also be designed for $\mathrm{Hg}^{2+}$ sensing based on the reaction between $\mathrm{Hg}^{2+}$ and vinyl ether, arylboronic acid.

Ando and co-workers designed and synthesized a novel strategy for $\mathrm{Hg}^{2+}$ detection in environmental samples based on vinyl ether oxymercuration [98]. The first generation probe 37a they designed can be applied for $\mathrm{Hg}^{2+}$ detection at a $1 \mathrm{ppb}$ level in river water and dental samples (Fig. 15). However, the detection conditions of probe 37a were harsh, and the probe needed to work in the acidic $\mathrm{pH}$ range of 3-4. And the $\mathrm{Hg}^{2+}$ detection by probe $37 \mathbf{a}$ was interfered by $\mathrm{Cl}^{-}$, and it was necessary to add silver nitrate to eliminate the interference from $\mathrm{Cl}^{-}$. In order to overcome the above shortcomings, researchers optimized the probe structure with vinyl ether and probe $37 \mathrm{~b}$ was obtained. After optimization, the interference of $\mathrm{Cl}^{-}$on the probe was reduced, and the reactivity of probe 37b towards $\mathrm{Hg}^{2+}$ was increased. Probe 37b exhibited desirable performance for $\mathrm{Hg}^{2+}$ detection with a LOD of $1 \mathrm{ppb}$. $\mathrm{Wu}$ and co-workers reported a turn-on fluorescent probe $\mathbf{3 8}$ for $\mathrm{Hg}^{2+}$ 

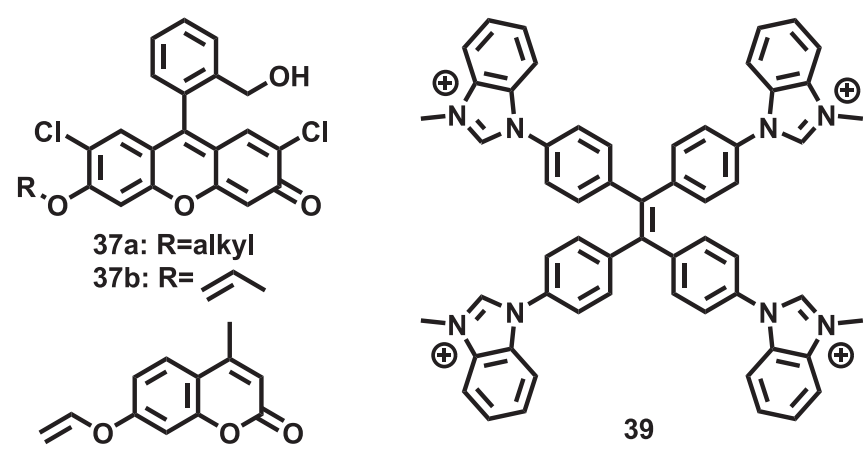

38

Fig. 15. Structures of 37-39.

sensing [99]. Coumarin was chosen as a fluorescence reporter, and vinyl ether unit was selected as a recognition site. Probe $\mathbf{3 8}$ exhibited no fluorescence signals in buffer solution. After adding $\mathrm{Hg}^{2+}$, it can promote the irreversible hydrolysis of vinyl ether, accompanied by fluorescence signal increased at $450 \mathrm{~nm}$. The sensing mechanism was verified by ${ }^{1} \mathrm{H}$ NMR analysis and MS analysis. The probe showed good water solubility, and the LOD of probe 38 can reach $0.12 \mu \mathrm{M}$. The probe also exhibited potential application value in water quality detection.

Yuan and co-workers developed a turn-on fluorescent probe $\mathbf{3 9}$ for $\mathrm{Hg}^{2+}$ sensing based on aggregation-induced emission [100]. They introduced four positively charged methylated benzimidazole units into the styrene structure to increase the water solubility of probe. The rotation of the $\mathrm{C}-\mathrm{C}$ bond between benzene ring, between benzene ring and benzimidazole, as well as the $\mathrm{C}-\mathrm{N}$ bond between benzimidazole not only reduced the planarity of the probe structure, but also increased the possibility of non-radiative transitions. Therefore, probe $\mathbf{3 9}$ had no fluorescence emission signals. Probe 39 can coordinate with $\mathrm{Hg}^{2+}$ or organic mercury, and mercury-mediated chelate ring formation as well as subsequent aggregation made probe $\mathbf{3 9}$ more rigid, accompanied by strong fluorescence signal emission. The complexing mechanism was verified by transmission electron microscopy, dynamic light scattering and resonance light scattering. The probe was further applied for $\mathrm{Hg}^{2+}$ selective sensing in living cells.

Based on the displacement reaction between arylboronic acid and $\mathrm{Hg}^{2+}$, Neupane and co-workers synthesized a new fluorescent probe 40 with enhanced fluorescence signal for $\mathrm{Hg}^{2+}$ detection (Fig. 16) [101]. They used dansyl as fluorophore, and probe $\mathbf{4 0}$ was synthesized after connected dansyl with phenylboronic acid through sulfonamide group. Researchers reported that the exchange reaction between boric acid and $\mathrm{Hg}^{2+}$ may enhance intramolecular charge transfer within the probe molecule, accompanied by an increase in fluorescence signal at $500 \mathrm{~nm}$. They explored the reaction mechanism through spectral testing, HPLC analysis, HPLC-MS analysis and ${ }^{1} \mathrm{H}$ NMR analysis. The probe showed desirable sensing performance, such as good selectivity, high sensitivity, fast response and low detection limit, which exhibited good application potential in $\mathrm{Hg}^{2+}$ analysis.

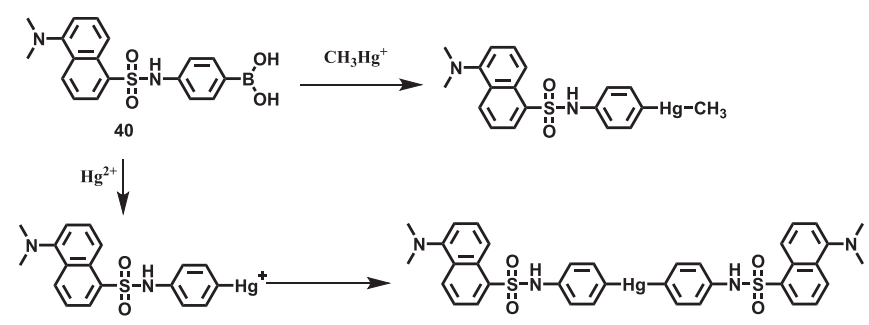

Fig. 16. The response mechanism of probe 40.

\section{Ratiometric fluorescent probes for $\mathrm{Hg}^{2+}$ analysis}

The fluorescence wavelength of ratiometric fluorescent probes will be red-shifted or blue-shifted after reacting with targets. Ratio determination of analyte can be achieved by calculating the ratio of signals at different fluorescence wavelengths. Ratiometric fluorescent probes have the following advantages: it can achieve self-correction and reduce the interference from various environmental factors such as photobleaching and instrument efficiency changes. Thus, the ratiometric fluorescent probes have high sensitivity. However, the acquisition operation of ratio fluorescence signals and the data processing operations are cumbersome. In addition, the fluorescence wavelength of ratiometric fluorescent probes should possess a large Stokes shift to reduce the fluorescence spectrum overlap and improve the sensitivity of the probe. In this section, we will introduce the ratiometric fluorescent probes based on the following reaction mechanisms: S-atom complexation, deprotection reaction of dithioacetals, rhodamine ring-opening reaction and $\mathrm{N}$-atom complexation.

\subsection{Fluorescent probes for $\mathrm{Hg}^{2+}$ analysis based on S-atom complexation}

Most of the developed fluorescent probes for $\mathrm{Hg}^{2+}$ detection were based on the increase or decrease in fluorescence signals. Tian group reported a ratiometric fluorescent probe $\mathbf{4 1}$ for $\mathrm{Hg}^{2+}$ selective detection (Fig. 17) [102]. They used benzoyl thiourea unit as response site, and probe 41 with yellow-green fluorescence emission was obtained after connected benzoyl thiourea unit to fluorophore 4-amino-1,8-naphthalimide through ethylene. $\mathrm{Hg}^{2+}$ can trigger intramolecular cyclization by reacting with thiourea, accompanied by the change in fluorescence emission wavelength from $530 \mathrm{~nm}$ to $475 \mathrm{~nm}$.

Tian and co-workers reported a ratiometric fluorescent probe $\mathbf{4 2}$ for $\mathrm{Hg}^{2+}$ selective detection with excellent water solubility [103]. They selected 9-amino-substituted acridizinium derivatives as fluorophore and 1,4-dioxa-7,13-dithia-10-azacyclopentadecane unit as response site to afford probe 42. The probe can be applied for $\mathrm{Hg}^{2+}$ detection in pure water without the requirement of organic cosolvent. However, the fluorescence quantum yield of probe $\mathbf{4 2}$ was reduced after reacted with $\mathrm{Hg}^{2+}$, and $\mathrm{Ag}^{+}$also caused interference during $\mathrm{Hg}^{2+}$ detection, which limited the practical applications of the probe.

Given the advantages of ratiometric fluorescent probe, Xuan and coworkers designed and synthesized a ratiometric fluorescent probe $\mathbf{4 3}$ for $\mathrm{Hg}^{2+}$ selective detection (Fig. 18) [104]. They used coumarin as the fluorophore based on the desirable stability and optical properties of coumarin. In order to expand the conjugate system of the probe $\mathbf{4 3}$ and obtain a larger spectral separation, they introduced a thioether functional group at the 3rd position of the coumarin framework. $\mathrm{Hg}^{2+}$ can induce desulfurization and elimination reactions after reacted with probe 43, and subsequently, an electron-withdrawing $\alpha, \beta$-unsaturated ketone was produced. The conjugate system was expanded and the fluorescence emission spectrum was red-shifted. Probe $\mathbf{4 3}$ can be employed for $\mathrm{Hg}^{2+}$ selective detection, and the reaction stoichiometry of probe 43 to $\mathrm{Hg}^{2+}$ was 2:1. The colorimetric changes caused by probe structure change can be visually observed, and the probe can be applied for $\mathrm{Hg}^{2+}$ detection in living cells.

Chen and co-workers synthesized a two-photon ratiometric fluorescent probe 44 for $\mathrm{Hg}^{2+}$ recognition [105]. Probe 44 contained a

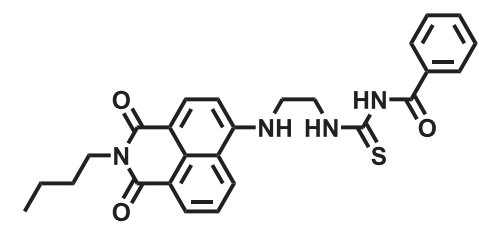

41

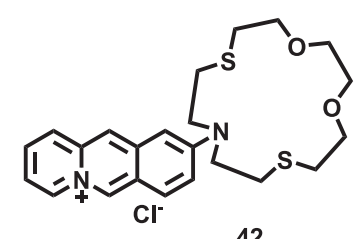

42
Fig. 17. Structures of 41 and 42. 


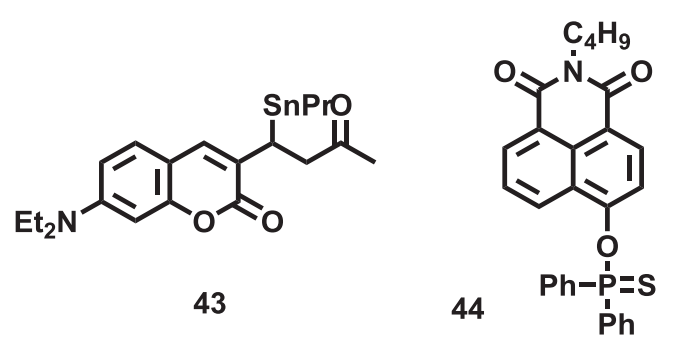

Fig. 18. Structures of 43 and 44 .

naphthalimide fluorophore and a diphenylphosphinothioyl response unit. $\mathrm{Hg}^{2+}$ can promote to crack the P-O bond of thiophosphinate in the probe, releasing product NAP-O with effective intramolecular charge transfer from the electron-donating oxy-anion site to the strong electronwithdrawing naphthalimide unit. And the recognition mechanism was confirmed by HRMS. In addition, probe 44 was applied for $\mathrm{Hg}^{2+}$ imaging in HeLa cells and rat liver tissues.

\subsection{Fluorescent probes for $\mathrm{Hg}^{2+}$ analysis based on deprotection of dithioacetals}

The aldehyde group protected by mercapto can only be converted to previous aldehyde unit again in the presence of $\mathrm{Hg}^{2+}$. Based on this principle, Cheng and co-workers designed and synthesized two fluorescent probes 45 (45a and 45b) for $\mathrm{Hg}^{2+}$ detection (Fig. 19) [106]. Probes 45 were obtained through the protection reaction of thiols on aldehydes. And the $\mathrm{Hg}^{2+}$ selective detection can be achieved through $\mathrm{Hg}^{2+}$-promoted deprotection reaction of thioacetals. Probes 45 can quickly respond to $\mathrm{Hg}^{2+}$, and probe 45a can be made into test strips which were easily used for actual samples detection. However, the probes had poor water solubility and the $\mathrm{Hg}^{2+}$ detection was interfered by $\mathrm{Ag}^{+}$, which limited the practical application of probe 45 . Anyway, the design strategy of probes provided researchers with new ideas.

Zhou and co-workers synthesized a ratiometric fluorescent probe 46
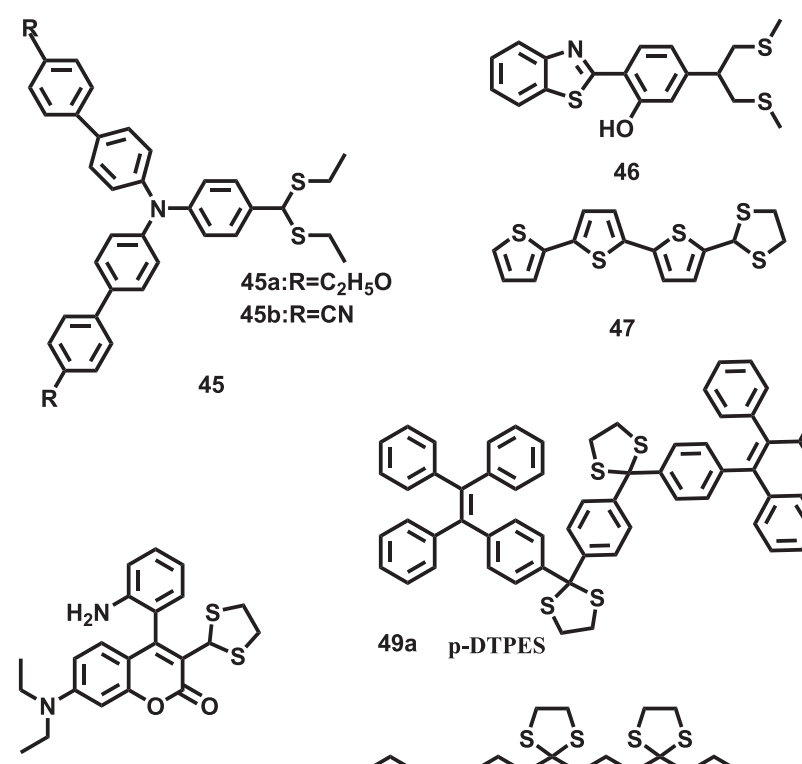

47

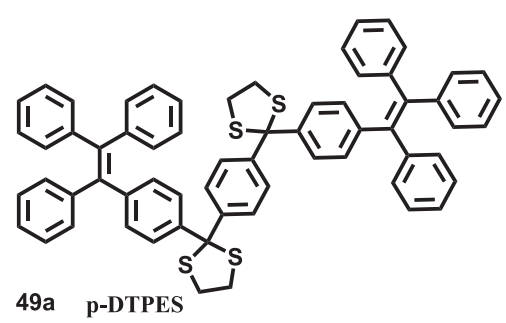

48

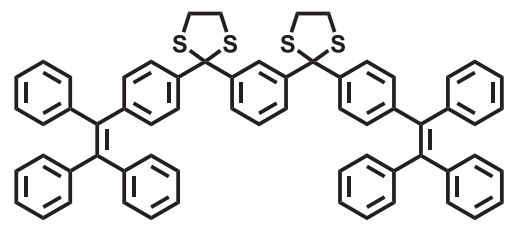

49b m-DTPES

Fig. 19. Structures of 45-49. for $\mathrm{Hg}^{2+}$ detection based excited-state intramolecular proton transfer/ intramolecular charge transfer modulation [107]. They selected 2-(2hydroxyphenyl)benzothiazole as the excited state intramolecular proton transfer (ESIPT) dyes skeleton and thioacetals as the recognition site. After addition of $\mathrm{Hg}^{2+}$, the electron-rich disulfide acetal unit was removed by $\mathrm{Hg}^{2+}$ and it converted into an electron-deficient aldehyde group. At the same time, the ICT process from benzothiazole (electron donor) to aldehyde (electron acceptor) caused a significant red shift in the fluorescence wavelength and provided ratiometric fluorescence signals. The response mechanism of probe 46 was confirmed by HRMS and ${ }^{1} \mathrm{H}$ NMR analysis. The probe exhibited excellent spectral performance and the LOD of probe 46 was as low as $5.8 \mathrm{nM}$.

Lan and co-workers reported a ratiometric fluorescent probe $\mathbf{4 7}$ for $\mathrm{Hg}^{2+}$ sensing based on deprotection reaction of thioacetals [108]. Probe 47 5-(1,3-dithiolan-2-yl)-2,2':5',2' - terthiophene was synthesized by Kumada coupling reaction and Vilsmeier reaction. After adding $\mathrm{Hg}^{2+}$, it triggered the deprotection reaction of acetal, and the dithioacetal group converted to aldehyde, accompanying the fluorescence signal at $450 \mathrm{~nm}$ decreased as well as fluorescence signal at $550 \mathrm{~nm}$ increased. The response mechanism was confirmed by ${ }^{1} \mathrm{H}$ NMR analysis, FT-IR analysis as well as spectrum analysis, and probe 47 was applied for $\mathrm{Hg}^{2+}$ detection in real water samples, shrimp, and fish.

Pan and co-workers developed a reaction-based ratiometric fluorescent probe $\mathbf{4 8}$ for $\mathrm{Hg}^{2+}$ determination via a "covalent assembly", strategy [109]. The pivotal design idea for probe $\mathbf{4 8}$ was to connect the $\mathrm{Hg}^{2+}$ response group 1,3-dithiolane unit into the ortho position of 2-aminophenyl unit, which would induce fluorescence signal changes of coumarin derivatives via the ICT mechanism. After addition of $\mathrm{Hg}^{2+}$, 1,3-dithiolane was transformed to formyl via desulfurization reaction, and it would condense with nearby amino groups $\left(-\mathrm{NH}_{2}\right)$ to produce the product c-ql. $-\mathrm{NH}_{2}$ can coordinate with $\mathrm{Hg}^{2+}$ and brought it closer to 1,3-dithiolane, which was beneficial to the intramolecular ring condensation reaction, and the product c-ql was a heterocyclic aromatic compound with a larger conjugate plane than the probe 48 . The reaction mechanism was verified by HRMS and ${ }^{1} \mathrm{H}$ NMR analysis. The theoretical detection limits of the probe for $\mathrm{Hg}^{2+}$ and $\mathrm{MeHg}^{+}$were $27 \mathrm{nM}$ and 5.8 $\mu \mathrm{M}$, respectively.

Ruan and co-workers reported two ratiometric fluorescent probes 49 (49a and 49b) based on aggregation-induced emission for $\mathrm{Hg}^{2+}$ sensing [110]. The probe 49 contained tetraphenylethene fluorophore and two thioketal moieties. $\mathrm{Hg}^{2+}$ can promote the deprotection reaction of thioketal and produced ratio fluorescent signals changes that visually observable from sky blue to yellow-green, thus probe 49 can achieve the $\mathrm{Hg}^{2+}$ selective detection. The probes can be manufactured test strips, and provided convenience for $\mathrm{Hg}^{2+}$ on-site real-time detection.

\subsection{Fluorescent probes for $\mathrm{Hg}^{2+}$ analysis based on rhodamine ring- opening reaction}

Ratiometric fluorescent probes with effective internal calibration can reduce interferences from the instrument and other external factors. Qian group designed and synthesized a ratiometric fluorescent probe $\mathbf{5 0}$ for $\mathrm{Hg}^{2+}$ selective detection by connected BODIPY dye with rhodamine dye using a rigid and conjugated phenyl-ethynyl-phenyl spacer (Fig. 20) [111]. BODIPY with lipophilicity was selected as energy donor, and rhodamine with hydrophilicity was chosen as energy acceptor. The fluorescence spectrum of BODIPY matched well with the absorption spectrum of rhodamine, and they were linked through a phenyl-ethynylphenyl spacer, which can promote the through-bond energy transfer process. Initially, probe $\mathbf{5 0}$ showed the maximum absorption peak at $488 \mathrm{~nm}$ and the maximum emission peak at $514 \mathrm{~nm}$. After reacted with $\mathrm{Hg}^{2+}$, the emission peak of probe $\mathbf{5 0}$ at $514 \mathrm{~nm}$ was decreased while a new emission peak at $589 \mathrm{~nm}$ was increased. The probe showed excellent selectivity towards $\mathrm{Hg}^{2+}$, and it can be applied for $\mathrm{Hg}^{2+}$ detection under physiological condition on the ppb scale.

$\mathrm{Ge}$ and co-workers designed and synthesized a FRET ratiometric 

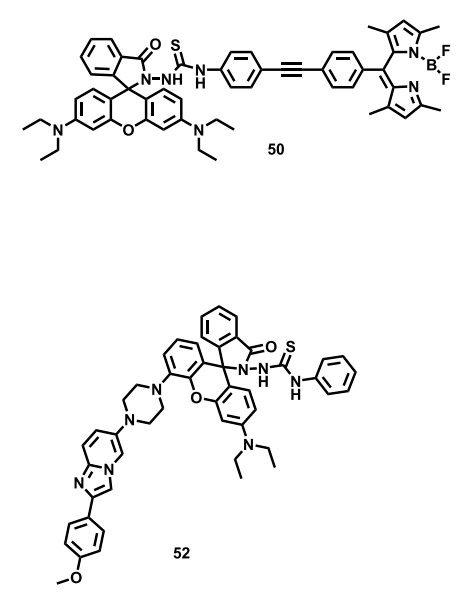
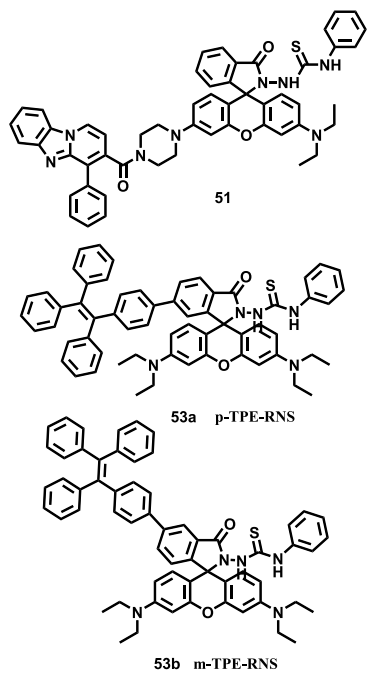

Fig. 20. Structures of $\mathbf{5 0 - 5 3 . ~}$

fluorescent probe $\mathbf{5 1}$ for $\mathrm{Hg}^{2+}$ detection based on pyrido[1,2-a] benzimidazole-rhodamine system [112]. In the molecular structure of probe 51, leuco-rhodamine derivative was selected as energy acceptor, and pyrido[1,2-a]benzimidazole was used as energy donor. The FRET efficiency calculated by donor fluorescence intensity detection was $87.3 \%$ in the presence or absence of the acceptor. Probe $\mathbf{5 1}$ had a large Stokes shift $(204 \mathrm{~nm})$, which can avoid interferences from spectral overlap. The LOD of probe 51 can reach $18.8 \mathrm{nM}$ and it can be used for $\mathrm{Hg}^{2+}$ detection in the $\mathrm{pH}$ range of 5-10.

$\mathrm{Li}$ and co-workers developed a ratiometric fluorescent probe $\mathbf{5 2}$ for $\mathrm{Hg}^{2+}$ selective sensing based on rhodamine open-ring [113]. They chose rhodamine as energy acceptor and imidazo[1,2-a]pyridine as energy donor because the emission spectrum of imidazo [1,2-a] pyridine overlapped with the absorption spectrum of rhodamine. Probe $\mathbf{5 2}$ without FRET mechanism displayed absorption and emission maximum at $370 \mathrm{~nm}$ and $436 \mathrm{~nm}$. After reacting with $\mathrm{Hg}^{2+}$, rhodamine underwent a ring-opening reaction and the FRET mechanism turned on, while the fluorescence signal at $436 \mathrm{~nm}$ was decreased and the fluorescence signal at $590 \mathrm{~nm}$ was enhanced. The probe showed a large Stokes shift of about $220 \mathrm{~nm}$, which can avoid fluorescence self-quenching effectively. The LOD of probe 52 was as low as $9.1 \mathrm{nM}$, and probe with superior spectral performance was applied for $\mathrm{Hg}^{2+}$ imaging in living cells.

Based on dark through-bond energy transfer, Tang group designed and synthesized ratiometric fluorescent probes $\mathbf{5 3}$ for $\mathrm{Hg}^{2+}$ sensing [114]. Obtaining large pseudo-Stokes shift may reduce the spectral overlap between donor emission and acceptor absorption, which can result in a decrease in FRET efficiency and donor energy leakage. A new design strategy, the through-bond energy transfer (TBET) mechanism, can be used as a desirable method to settle this contradiction. There was a torsion angle between the donor and acceptor, avoiding being regarded as a fluorophore. Compared with the traditional FRET system, the energy transfer rate of TBET can be 2 orders of magnitude faster, thereby reducing the dependence on spectral overlap. Therefore, even if there was a small spectral overlap, researchers can easily realize high energy transfer efficiency and analyze targets through the TBET mechanism, which was beneficial for producing large pseudo Stokes shift. Tetraphenylethene (TPE) had less fluorescence emission because the rapid non-radiative decay in solution, TPE was also easy to modify and TPE derivatives usually had big Stokes shifts. After suppressing non-radiation decay, TPE derivatives had higher signal emission in the aggregate state, thus researchers chose TPE as the dark donor. Rhodamine B derivatives with high quantum yield and large molar absorbance coefficient had been developed for designing various fluorescent probes, thus rhodamine B derivative was selected as acceptors. Researchers designed two probes used thiosemicarbazides for $\mathrm{Hg}^{2+}$ high specifically recognition. Probes with hydrophobicity tended to form aggregates in solution. Rhodamine existed in the form of spironolactone, thus the probes emitted blue fluorescence of the TPE backbone. After addition of $\mathrm{Hg}^{2+}$, the solubility of positively charged rhodamine in solution was increased. Due to the dark through-bond energy transfer process as well as nonradiative decay, the fluorescence of TPE cannot be observed, and the strong fluorescence signal from rhodamine can be observed. This reasonable design strategy can achieve ratiometric $\mathrm{Hg}^{2+}$ measurement. Probe had great pseudo Stokes shifts more than $280 \mathrm{~nm}$ and 240 for 53a and 53b respectively, which was favorable for imaging analysis. After adding $\mathrm{Hg}^{2+}$, the signal was enhanced more than 6000 times, and the LOD can reach $0.3 \mathrm{ppb}$. This research provides a novel strategy for the design of $\mathrm{Hg}^{2+}$ fluorescent probes.

\subsection{Fluorescent probes for $\mathrm{Hg}^{2+}$ analysis based on $\mathrm{N}$-atom complexation}

To solve the problem of spectral overlap, Zhang group designed and synthesized a novel ratiometric fluorescent probe $\mathbf{5 4}$ for $\mathrm{Hg}^{2+}$ selective detection with excellent spectral separation (Fig. 21) [115]. They selected naphthalimide derivative as chromophore due to its superior quantum yield and stability, porphyrin was chosen as response site for seizing $\mathrm{Hg}^{2+}$. After linked naphthalimide derivative with porphyrin, probe 54 was obtained and it had two well-separated fluorescence peaks with a $125 \mathrm{~nm}$ difference (from $650 \mathrm{~nm}$ blue-shifted to $525 \mathrm{~nm}$ ). The probe displayed reversible fluorescence response towards $\mathrm{Hg}^{2+}$, and it can be applied for $\mathrm{Hg}^{2+}$ detection in living cells.

Jiang and co-workers reported a ratiometric fluorescent probe $\mathbf{5 5}$ based ICT mechanism for $\mathrm{Hg}^{2+}$ analysis [116]. They selected 4-aminonaphthalimide as the fluorescence reporter for its outstanding photophysical properties, and a vinyl enol ether subunit was chosen as response unit for its desirable selectivity for $\mathrm{Hg}^{2+}$ detection, and they were connected using a carbamate group. Probe $\mathbf{5 5}$ exhibited superior selectivity towards organic mercury and inorganic mercury without interference from other ions. The probe was stable in the $\mathrm{pH}$ range of 2.17-11.13, and it can be used for $\mathrm{Hg}^{2+}$ detection in living cells.

Jiao and co-workers reported a ratiometric fluorescent probe $\mathbf{5 6}$ based on schiff-base for $\mathrm{Hg}^{2+}$ sensing [117]. Probe 56 contained a coumarin dye and a 5-aminoisophthalic acid methyl ester chromophore, and the schiff-base $\mathrm{C}=\mathrm{N}$ site was used for $\mathrm{Hg}^{2+}$ response. Probe $\mathbf{5 6}$ emitted weak fluorescence signal because of the photoinduced electron transfer process. After addition of $\mathrm{Hg}^{2+}$, the $\mathrm{C}=\mathrm{N}$ bond hydrolysis reaction occurred and strong fluorescence signal was emitted. The probe showed good spectral response and can be utilized for intracellular $\mathrm{Hg}^{2+}$
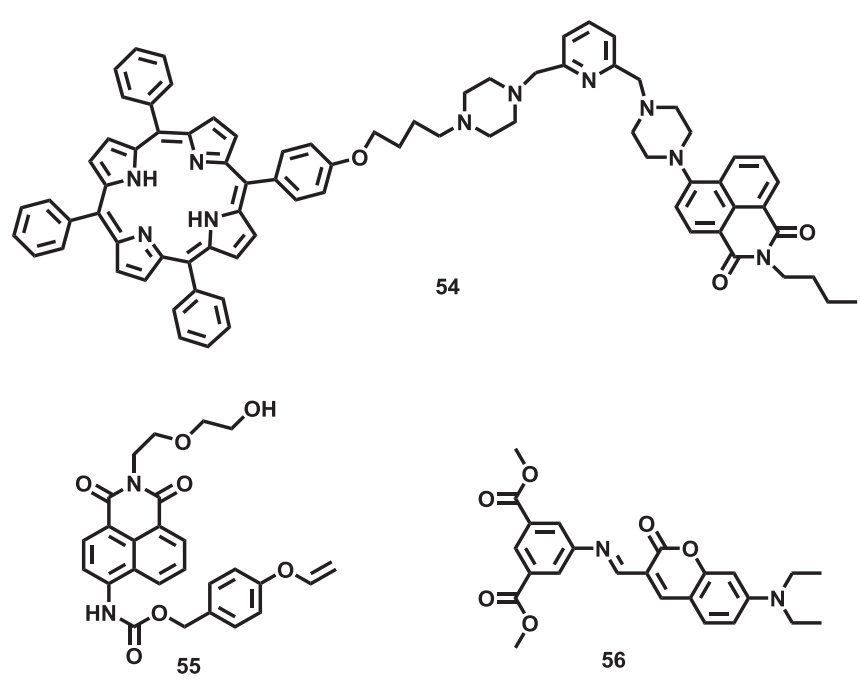

Fig. 21. Structures of 54-56. 
detection.

\section{Fluorescent probes for $\mathrm{Hg}^{2+}$ and other species analysis}

Designing fluorescent probes for selectively analyzing individual species is relatively simple. However, multiple species may participate and act in a complex physiological process in environment and organisms. Therefore, multi-responsive fluorescent probes for two or more species detection are valuable, which also poses challenges for probe design. In this section, we will introduce fluorescent probes that are applied for $\mathrm{Hg}^{2+}$ and other species analysis.

The BODIPY unit and porphyrin unit showed effective energy transfer characteristics, and the stoke shift between BODIPY unit and porphyrin unit in the maximum fluorescence emission peak was large enough, thus they had great potential in designing FRET ratiometric probes. Chen and co-workers reported a versatile fluorescent probe $\mathbf{5 7}$ for $\mathrm{Hg}^{2+}$ and $\mathrm{Fe}^{2+}$ detection (Fig. 22) [118]. They connected BODIPY unit with porphyrin unit to afforded probe $57 . \mathrm{Hg}^{2+}$ can reduce the ratio fluorescence signals of probe 57, while $\mathrm{Fe}^{2+}$ increased the ratio fluorescence signals of the probe. The association constants of probe towards $\mathrm{Hg}^{2+}$ and $\mathrm{Fe}^{2+}$ were $3.5 \times 10^{6}$ and $2.2 \times 10^{6}$ respectively, which showed practical application potential of the probe for environmental samples.

Shen et al. reported a triphenylamine-BODIPY based Schiff base fluorescent probe $\mathbf{5 8}$ for $\mathrm{Hg}^{2+}$ and $\mathrm{Fe}^{3+}$ detection [119]. The introduction of 4-hydroxystyrene at the 3,5-positions of the triphenylamineBODIPY core can expand the conjugate system of probe to achieve near infrared fluorescence emission, while Schiff base was also introduced to afforded a new probe $\mathbf{5 8}$ for $\mathrm{Hg}^{2+}$ and $\mathrm{Fe}^{3+}$ detection. Due to the non-radiative attenuation caused by $\mathrm{C}=\mathrm{N}$ isomerization and rotation, probe 58 showed weak fluorescence signals. After addition of $\mathrm{Hg}^{2+}$ or $\mathrm{Fe}^{3+}$, the Schiff base underwent hydrolysis which further resulted in the conversion of $\mathrm{C}=\mathrm{N}$ group to the formyl group, and the fluorescence

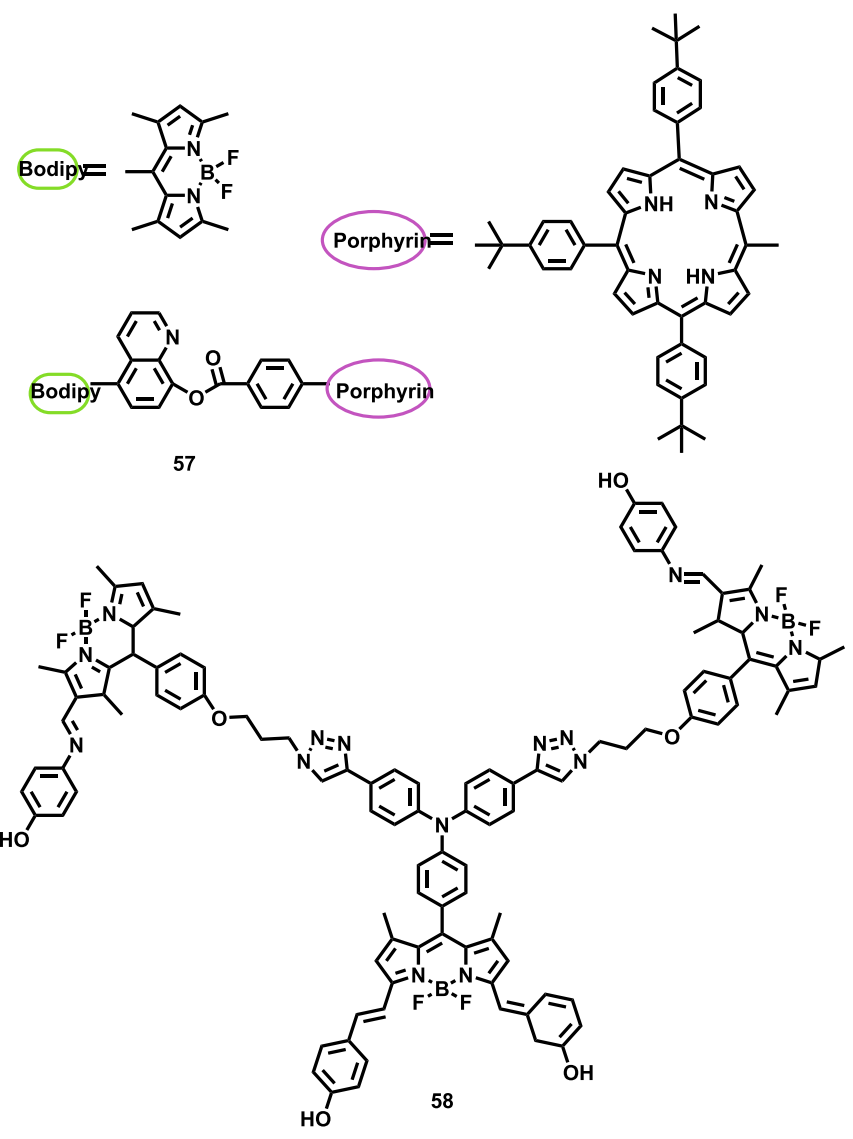

Fig. 22. The structures of probe $\mathbf{5 7}$ and $\mathbf{5 8}$. signal from probe $\mathbf{5 8}$ was enhanced. The stoichiometry between probe 58 and $\mathrm{Fe}^{3+} / \mathrm{Hg}^{2+}$ were $1: 3$ and $1: 2$, and the LOD of probe $\mathbf{5 8}$ were $5.15 \times 10^{-7} \mathrm{M}$ and $6.81 \times 10^{-7} \mathrm{M}$ respectively. The probe had great application potential in the field of ion detection and biomedicine after encapsulated as nanoparticles, and the probe can be employed for $\mathrm{Hg}^{2+}$ and $\mathrm{Fe}^{3+}$ detection in solution and living cells.

Gao et al. reported a fluorescent probe $\mathbf{5 9}$ based on Schiff-base for $\mathrm{Hg}^{2+}$ and $\mathrm{Cu}^{2+}$ sensing (Fig. 23) [120]. Probe 59 was synthesized using benzimidazole and coumarin fluorophores. After addition of $\mathrm{Hg}^{2+}$, the $\mathrm{C}=\mathrm{N}$ bond was broken and hydrolyzed, and the new compound coumarin derivative and benzimidazole-Hg complex were finally formed. However, $\mathrm{Cu}^{2+}$ can complex with probe $\mathbf{5 9}$ to quench the fluorescence signals from probe $\mathbf{5 9}$. Therefore, probe $\mathbf{5 9}$ can effectively distinguish $\mathrm{Hg}^{2+}$ and $\mathrm{Cu}^{2+}$, and it can be used for intracellular imaging.

$\mathrm{Gu}$ and co-workers reported a fluorescent probe $\mathbf{6 0}$ based on benzothiazole for distinguishing $\mathrm{Hg}^{2+}$ and $\mathrm{Cu}^{2+}$ [121]. Probe 60 contained two different recognition sites. The thioacetal unit was used for $\mathrm{Hg}^{2+}$ detection based $\mathrm{Hg}^{2+}$-induced dithioacetal deprotection, the $\mathrm{O}$ and $\mathrm{N}$ atoms in benzothiazole group was applied for $\mathrm{Cu}^{2+}$ sensing. Probe 60 emitted strong green fluorescent signals at $530 \mathrm{~nm}$. After reacted with $\mathrm{Hg}^{2+}$, the fluorescence signal at $530 \mathrm{~nm}$ decreased and a new fluorescence peak at $545 \mathrm{~nm}$ increased gradually. However, the quenching reaction occurred after the addition of $\mathrm{Cu}^{2+}$. The reaction mechanism of probe 60 was verified by the spectra analysis, MS analysis and ${ }^{1} \mathrm{H}$ NMR titration analysis.

For $\mathrm{O}_{2}^{--}$and $\mathrm{Hg}^{2+}$ detection, Chen group designed two fluorescent probes (61 and 62) based on cyanine fluorophore for $\mathrm{O}_{2}^{--}$and $\mathrm{Hg}^{2+}$ associated-detection via three-channel fluorescence signals (Fig. 24) $[15,16]$. Probe $\mathbf{6 1}$ contained cyanine fluorophore and selenol group. After reacted with $\mathrm{NaBH}_{4}$, the conjugated system of the cyanine fluorophore was interrupted, therefore probe $\mathbf{6 1}$ didn't emit fluorescence signals. The fluorescence signal from probe $\mathbf{6 1}$ can be selectively turned on by $\mathrm{O}_{2}^{\circ-}$, thereby probe $\mathbf{6 1}$ can be applied for $\mathrm{O}_{2}^{--}$selective detection. Then, selenol-responsive unit can further achieve $\mathrm{Hg}^{2+}$ detection via selenium-mercury antagonism reaction. Probe $\mathbf{6 1}$ can be employed for associated-detection of $\mathrm{O}_{2}^{--}$and $\mathrm{Hg}^{2+}$ in living cells and model mice. Next, to improve the stability of the probe structure, they changed the response group, selenol group, to a more stable thiol unit to afforded probe $\mathbf{6 2}$. The stability of probe $\mathbf{6 2}$ was improved, and it can be applied for $\mathrm{O}_{2}^{--}$and $\mathrm{Hg}^{2+}$ selective detection. Furthermore, probe 62 can be applied for $\mathrm{O}_{2}^{\circ-}$ and $\mathrm{Hg}^{2+}$ detection in living cells, and it can be employed for comparative studies of acute mercury poisoning and chronic mercury poisoning in mice models.

$\mathrm{Hu}$ and co-workers reported a turn-on fluorescent probe $\mathbf{6 3}$ for $\mathrm{Hg}^{2+}$ and $\mathrm{Pb}^{2+}$ detection based on a rhodamine-phenylurea conjugate (Fig. 25) [122]. The probe can achieve $\mathrm{Pb}^{2+}$ detection in $\mathrm{CH}_{3} \mathrm{CN}$ and $\mathrm{Hg}^{2+}$ detection in aqueous media. Probe had good selectivity and high sensitivity towards $\mathrm{Pb}^{2+}$ and $\mathrm{Hg}^{2+}$, and the LOD of probe 63 for $\mathrm{Pb}^{2+}$ and $\mathrm{Hg}^{2+}$ were $7 \times 10^{-9}$ as well as $3.5 \times 10^{-8} \mathrm{M}$, respectively.

Based on desulfurization reaction, researchers have designed some desirable fluorescent probes for $\mathrm{Hg}^{2+}$ analysis. Tsukamoto and coworkers provided a novel concept that improved desulfurization susceptibility of 7-hydroxy-3-thioureidocoumarin by proper substituent
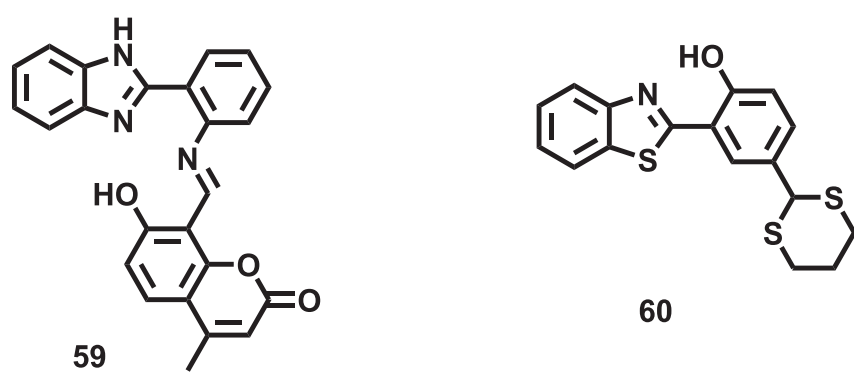

60

Fig. 23. Structures of 59-60. 


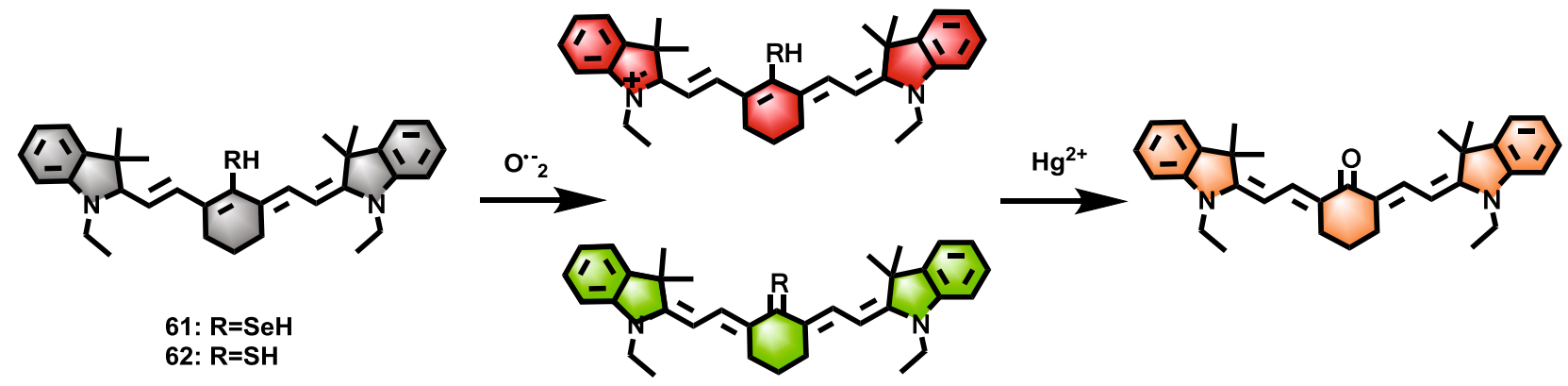

Fig. 24. The response mechanism of probe 61 and 62 for $\mathrm{O}_{2}^{--}$and $\mathrm{Hg}^{2+}$ sensing.

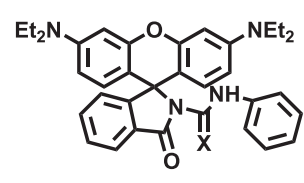

RPU: $X=0$
RPTU: $X=S$

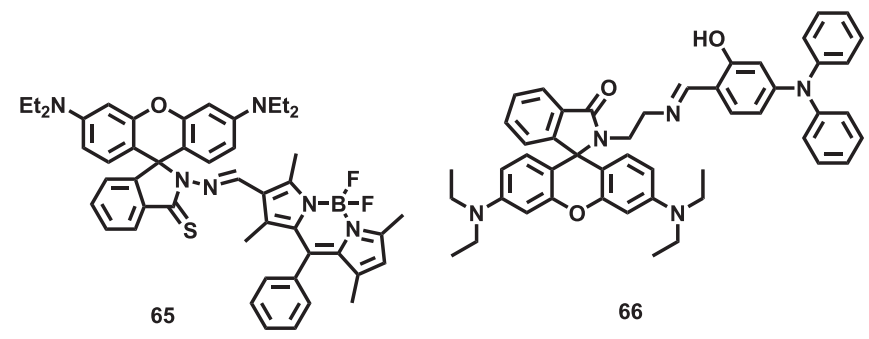

Fig. 25. Structures of 63-66.

[123]. They selected coumarin as fluorescence reporter and N'-acetylthioureido group as response site to construct probe 64 for $\mathrm{Hg}^{2+}$ and $\mathrm{Ag}^{+}$analysis. The hydrogen bond formed in the probe between the $\mathrm{N}-$ hydrogen and the acetyl $\mathrm{O}$ atom can effectively increase the susceptibility of desulfurization between probe and $\mathrm{Hg}^{2+}$ as well as $\mathrm{Ag}^{+}$. The high susceptibility of desulfurization by $\mathrm{Hg}^{2+}$ was confirmed by X-Ray crystallography and ${ }^{1} \mathrm{H}$ NMR analysis. At first, no fluorescence signal was emitted from probe 64. After addition of $\mathrm{Hg}^{2+}$, strong fluorescence signals from probe 64 were emitted and the fluorescence signals can quickly reach saturation within $2 \mathrm{~min}$. Similarly, probe 64 can quickly respond to $\mathrm{Ag}^{+}$with fluorescence increase. The LOD of probe 64 for $\mathrm{Hg}^{2+}$ and $\mathrm{Ag}^{+}$were $2 \mathrm{ppb}$ and $1 \mathrm{ppb}$, respectively. In addition, the authors proposed two methods to distinguish $\mathrm{Hg}^{2+}$ from $\mathrm{Ag}^{+}$. One way was to control the $\mathrm{pH}$ value, and the other way was to add $\mathrm{Cl}^{-}$.

Karakus and co-workers reported a rhodamine/BODIPY-based fluorescent probe 65 for $\mathrm{Hg}^{2+}$ and $\mathrm{Au}^{3+}$ detection [124]. Initially, the rhodamine structure in the probe existed in the closed-ring form, and the probe didn't emit fluorescent signals. The reason can be attributed to the rapid isomerization of $\mathrm{C}=\mathrm{N}$ group in BODIPY core, which may reduce the fluorescence emission of BODIPY due to the non-radiative deactivation process. After addition of $\mathrm{Hg}^{2+}$, rhodamine existed in the ringopened isomeric form and it emitted strong fluorescence signals at $585 \mathrm{~nm}$. In addition, probe can achieve $\mathrm{Au}^{3+}$ detection based on the hydrolysis reaction. The probe possessed good cell membrane compatibility and it can be used for cell imaging analysis.

For $\mathrm{Hg}^{2+}$ and $\mathrm{Al}^{3+}$ sensing, Erdemir reported a new probe 66 based on the connection of aldehyde derivative of triphenylamine and rhodamine [125]. Probe 66 can realize $\mathrm{Al}^{3+}$ and $\mathrm{Hg}^{2+}$ detection through "PET-off" and "FRET-on" mechanisms, respectively. The LOD of probe 66 towards $\mathrm{Al}^{3+}$ and $\mathrm{Hg}^{2+}$ were $71.8 \mathrm{nM}$ and $0.48 \mu \mathrm{M}$, respectively. To facilitate detection, the authors produced test strips using probe 66 , and it can achieve $\mathrm{Hg}^{2+}$ and $\mathrm{Al}^{3+}$ detection conveniently.
$\mathrm{Hu}$ and co-workers designed and synthesized three fluorescent probes 67 (MP, FP, and FMP) for $\mathrm{Hg}^{2+}$ and $\mathrm{F}^{-}$detection (Fig. 26) [126]. Among the three probes, probe MP can realize $\mathrm{Hg}^{2+}$ selective sensing based on $\mathrm{Hg}^{2+}$-promoted desulfurization, and probe $\mathrm{FP}$ can realize $\mathrm{F}^{-}$ selective detection based on $\mathrm{F}^{-}$-triggered desilylation, while probe FMP emitted strong fluorescence signal after reacted with $\mathrm{Hg}^{2+}$ and $\mathrm{F}^{-}$. The LOD of probes 67 towards $\mathrm{Hg}^{2+}$ and $\mathrm{F}^{-}$were $4.0 \times 10^{-8} \mathrm{M}$ and $1.14 \times 10^{-}$ ${ }^{6} \mathrm{M}$, respectively. Researchers considered that the "AND" logic gate of FMP may have potential applications in molecular device development. Furthermore, the probe was applied for cell imaging successfully.

\section{Challenges and prospects}

In this feature article, we summarized the design strategies, performance and applications of the recent developed fluorescent probes for $\mathrm{Hg}^{2+}$ detection. Probes for $\mathrm{Hg}^{2+}$ detection are assorted by fluorescence signal response types: signal-decreased fluorescent probes, signalenhanced fluorescent probes and ratiometric fluorescent probes. Moreover, multi-responsive fluorescent probes that can simultaneously detect $\mathrm{Hg}^{2+}$ and other species are also summarized. In each section, fluorescent probes are introduced according to design strategies, for example $\mathrm{Hg}^{2+}$. promoted rhodamine ring-opening reaction, deprotection reaction of dithioacetals, desulfurization reaction, sulfur-complex reaction and nitrogen-complex reaction.

Recently, the development of fluorescent probes for $\mathrm{Hg}^{2+}$ detection significantly promoted fluorescence imaging analysis technology. Compared with the traditional analysis technology, $\mathrm{Hg}^{2+}$ detection based on fluorescent probes have distinct advantages, such as simple test steps, real-time online monitoring and less interference from environment or organisms. Despite the developed fluorescent probes providing convenience for $\mathrm{Hg}^{2+}$ detection in environmental samples and biological samples, several obstacles for fluorescent probes in selectivity, sensitivity and applications need to be overcome. Now the majority of

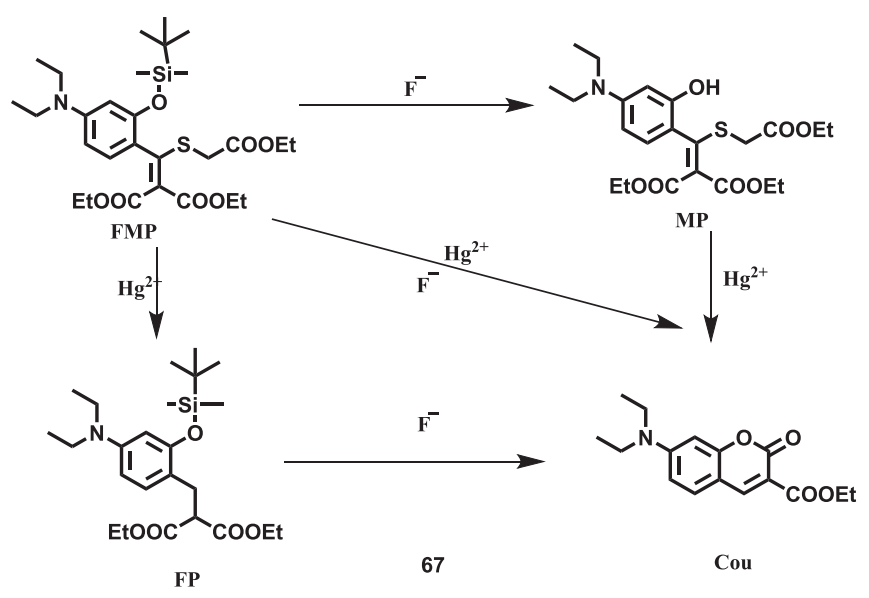

Fig. 26. The response mechanism of probe 67 for $\mathrm{Hg}^{2+}$ and $\mathrm{F}^{-}$sensing. 
fluorescent probes for $\mathrm{Hg}^{2+}$ detection are based on the response between sulfur, nitrogen, or oxygen atoms and $\mathrm{Hg}^{2+}$. However, these atoms usually interact with other species that may interfere with $\mathrm{Hg}^{2+}$ detection. Therefore, specific fluorescent probes for $\mathrm{Hg}^{2+}$ selective detection should be ingeniously designed. Additionally, fluorescent probes should have appropriate hydrophilicity and lipophilicity considering the complexity of the actual application environment. For $\mathrm{Hg}^{2+}$ sensing in organisms, probes attached with targeting functions groups are more valuable for exploring the distribution of $\mathrm{Hg}^{2+}$ in vivo. Moreover, distinguishing inorganic mercury ions $\left(\mathrm{Hg}^{2+}\right)$ and organic mercury is meaningful and challenging.

Considering the complexity of environmental conditions and organism milieu, developing novel fluorescent probe for $\mathrm{Hg}^{2+}$ selectively detection suffer from challenges, such as perturbation from endogenous active species, cell leakage and photostability. Fluorescent probe usually synthesized from organic molecule skeletons, which may suffer poor stability. Therefore it's urgent to improve the stability of fluorescent probes, including photon-stability and hydrolytic stability. Improving specific selectivity for $\mathrm{Hg}^{2+}$ detection and decreasing the interference from other species are meaningful. There are various forms of mercury, and it is also valuable for distinguishing determination of mercury with different forms, such as $\mathrm{Hg}^{2+}$ and methylmercury. Furthermore, multiresponse probes are attractive though they require ingenious probe design. $\mathrm{Hg}^{2+}$ as toxic heavy metal ion seriously interferes with normal physiological activities in organism, and designing powerful probe tools is of great significance for studying the effects of $\mathrm{Hg}^{2+}$ on organism health. The convenient probe test strips for environmental samples detection have drawn lots of attention and little progress in this field means a lot. In short, there are many interesting things worthy to do in the field of mercury imaging analysis.

Overall, mastering basic concepts and design strategies is necessary for developing superior fluorescent probes. A superior fluorophore should possess the following features: 1) good biocompatibility; 2) superior stability; 3) high quantum yield; 4) suitable emission spectrum wavelength range; 5) favorable chemical modifiability, etc. The response groups should specifically recognize targets and then show the detection signals through fluorophore. During responsive groups screening, selectivity and sensitivity are important considerations. The response units should not only exclusively respond to the target analytes without being influenced by potential interferes, but also have high sensitivity for low-level targets analysis. Moreover, the positioning groups can realize the targets analysis at specific sites through targeting specific organ or subcellular organelle. The applications of fluorescent probes, especially in environmental samples and biological imaging analysis, are the ultimate goal.

\section{Summary}

Fluorescent probe analysis technology with superior selectivity and high sensitivity has unique advantages for ions and molecules in situ real-time analysis. In this feature article, we summarize the fluorescent probes for $\mathrm{Hg}^{2+}$ detection, and they are classified according to the response modes of probe signals. We focus on probe design strategies, performance and applications of the fluorescent probes. Fluorescent probes exhibited superior performance for $\mathrm{Hg}^{2+}$ detection in complex aqueous medium, and they also can achieve rapid in situ detection in cells and in vivo. Differentiated detection of various forms of mercury is challenging but meaningful. The production of portable test strips is an extremely promising practical application of fluorescent probes. We strongly believe that the application range of fluorescent probes will be further expanded by drawing on the research results of $\mathrm{Hg}^{2+}$ fluorescent probes and combining with the new probe design strategies.

\section{Declaration of Competing Interest}

The authors declare that they have no known competing financial interests or personal relationships that could have appeared to influence the work reported in this paper.

\section{Acknowledgment}

This work was supported by the National Nature Science Foundation of China (Grant No. 21976209, 21778026 and 21804010), the program of Youth Innovation Promotion Association, CAS (Grant No. 2019217), the Research Initiation Fund of Binzhou Medical University (Grant No. BY2019KYQD39) and Taishan Scholar Project Special Funding (Grant No. ts20190962).

\section{Declaration of Competing Interest}

The authors declare no competing financial interest.

\section{References}

[1] B. Hu, L.L. Hu, M.L. Chen, J.H. Wang, A FRET ratiometric fluorescence sensing system for mercury detection and intracellular colorimetric imaging in live Hela cells, Biosens. Bioelectron. 49 (2013) 499-505.

[2] W.-H. Schroeder, J. Munthe, Atmospheric mercury-an overview, Atmos. Environ. 32 (1998) 809-822.

[3] Wang, L., Wang, M., Li, Z., Gong, Y. 2020. Enhanced removal of trace mercury from surface water using a novel Mg2Al layered double hydroxide supported iron sulfide composite. Chem. Eng. J., 124635.

[4] Y. Wang, L. Zhang, L. Chen, Glutathione peroxidase-activatable two-photon ratiometric fluorescent probe for redox mechanism research in aging and mercury exposure mice models, Anal. Chem. 92 (2019) 1997.

[5] Liu, D., Li, C., Wu, J., Liu, Y. 2019. Novel carbon-based sorbents for elemental mercury removal from gas streams: A review. Chem. Eng. J., 123514.

[6] Z. Zhang, J. Li, X. Song, J. Ma, L. Chen, $\mathrm{Hg}^{2+}$ ion-imprinted polymers sorbents based on dithizone- $\mathrm{Hg}^{2+}$ chelation for mercury speciation analysis in environmental and biological samples, RSC Adv. 4 (2014) 46444-46453.

[7] L. Yan, Z. Chen, Z. Zhang, C. Qu, L. Chen, D. Shen, Fluorescent sensing of mercury (II) based on formation of catalytic gold nanoparticles, Analyst 138 (2013) $4280-4283$.

[8] W. Liu, X. Wang, Y. Wang, J. Li, D. Shen, Q. Kang, L. Chen, Ratiometric fluorescence sensor based on dithiothreitol modified carbon dots-gold nanoclusters for the sensitive detection of mercury ions in water samples, Sensor. Actuat. B-Chem. 262 (2018) 810-817.

[9] X. Guo, F. Chen, F. Wang, Y. Wu, Y. Ying, Y. Wen, Q. Ke, Recyclable Raman chip for detection of trace Mercury ions, Chem. Eng. J. 390 (2020), 124528.

[10] X. Zhang, Y. Jiang, M. Zhu, Y. Xu, Z. Guo, J. Shi, D. Wang, Electrochemical DNA sensor for inorganic mercury (II) ion at attomolar level in dairy product using $\mathrm{Cu}$ (II)-anchored metal-organic framework as mimetic catalyst, Chem. Eng. J. 383 (2020), 123182.

[11] J. Li, K.G. Drouillard, B. Branfireun, G.D. Haffner, Comparison of the Toxicokinetics and Bioaccumulation Potential of Mercury and Polychlorinated Biphenyls in Goldfish (Carassius auratus), Environ. Sci. technol. 49 (2015) 11019-11027.

[12] O.J. Paris, J.P. Swaddle, D.A. Cristol, Exposure to Dietary Methyl-Mercury Solely during Embryonic and Juvenile Development Halves Subsequent Reproductive Success in Adult Zebra Finches, Environ. Sci. Technol. 52 (2018) 3117-3124.

[13] Y. Wang, L. Chen, Quantum dots, lighting up the research and development of nanomedicine, Nanomed - Nanotechnol. 7 (2011) 385-402.

[14] T.W. Clarkson, The toxicology of mercury, Crit. Rev. Cl. Lab. Sci. 34 (1997) 369-403.

[15] Y. Wang, M. Gao, Q. Chen, F. Yu, G. Jiang, L. Chen, Associated Detection of Superoxide Anion and Mercury(II) under Chronic Mercury Exposure in Cells and Mice Models via a Three-Channel Fluorescent Probe, Anal. Chem. 90 (2018) 9769-9778.

[16] Y. Wang, M. Gao, C. Liao, F. Yu, L. Chen, A sulfydryl-based near-infrared ratiometic fluorescent probe for assessment of acute/chronic mercury exposure via associated determination of superoxide anion and mercury ion in cells and in vivo, Sensor. Actuat. B-Chem. 301 (2019), 127038.

[17] D. Tran, A.J. Moody, A.S. Fisher, M.E. Foulkes, A.N. Jha, Protective effects of selenium on mercury-induced DNA damage in mussel haemocytes, Aquat. Toxicol. 84 (2007) 11-18.

[18] J. Wang, B. Liu, Highly sensitive and selective detection of $\mathrm{Hg}^{2+}$ in aqueous solution with mercury-specific DNA and Sybr Green I, Chem. Commun. 39 (2008) 4759-4761.

[19] Y. Li, Y. Jiang, X.P. Yan, Probing mercury species - DNA interactions by capillary electrophoresis with on-line electrothermal atomic absorption spectrometric detection, Anal. Chem. 78 (2006) 6115-6120.

[20] Richard Pilsner, J., Lazarus, A. L., NAM, D. H., Letcher, R. J., Sonne, C., Dietz, R., Basu, N. 2010. Mercury - associated DNA hypomethylation in polar bear brains via the LUminometric Methylation Assay: a sensitive method to study epigenetics in wildlife. Mol. Ecol., 19, 307-314. 
[21] X. Tan, C. Tang, A.F. Castoldi, L. Manzo, L.G. Costa, Effects of inorganic and organic mercury on intracellular calcium levels in rat T lymphocytes, J. Toxicol. Env. Heal. A 38 (1993) 159-170.

[22] E.M. Oliveira, D.V. Vassallo, J.J.F. Sarkis, J.G. Mill, Mercury effects on the contractile activity of isolated heart muscle, Toxicol. Appl. Pharm. 128 (1994) 86-91.

[23] T. Lou, L. Chen, C. Zhang, Q. Kang, H. You, D. Shen, L. Chen, A simple and sensitive colorimetric method for detection of mercury ions based on antiaggregation of gold nanoparticles, Anal. Meth. 4 (2012) 488-491.

[24] J. Qi, B. Li, X. Wang, Z. Zhang, Z. Wang, J. Han, L. Chen, Three-dimensional paper-based microfluidic chip device for multiplexed fluorescence detection of $\mathrm{Cu}^{2+}$ and $\mathrm{Hg}^{2+}$ ions based on ion imprinting technology, Sensor. Actuat. B-Chem 251 (2017) 224-233.

[25] A.C. Elia, R. Galarini, M.I. Taticchi, A.J.M. Dörr, L. Mantilacci, Antioxidant responses and bioaccumulation in Ictalurus melas under mercury exposure, Ecotox. Environ. Safe. 55 (2003) 162-167.

[26] G. Olivieri, C. Brack, F. Müller-Spahn, H.B. Stähelin, M. Herrmann, P. Renard, C. Hock, Mercury induces cell cytotoxicity and oxidative stress and increases $\beta$ amyloid secretion and tau phosphorylation in SHSY5Y neuroblastoma cells, J. Neurochem. 74 (2000) 231-236.

[27] P. Kaur, M. Aschner, T. Syversen, Glutathione modulation influences methyl mercury induced neurotoxicity in primary cell cultures of neurons and astrocytes, Neurotoxicology 27 (2006) 492-500.

[28] A. Becker, K.F. Soliman, The role of intracellular glutathione in inorganic mercury-induced toxicity in neuroblastoma cells, Neurochem. Res. 34 (2009) $1677-1684$.

[29] X. Gao, M. Li, Y. Zhao, Y. Zhang, Mechanistic study of selective adsorption of $\mathrm{Hg}^{2}$ + ion by porous alginate beads, Chem. Eng. J. 378 (2019), 122096.

[30] K. Yin, Q. Wang, M. Lv, L. Chen, Microorganism remediation strategies towards heavy metals, Chem. Eng. J. 360 (2019) 1553-1563.

[31] Y. Huang, S. Xia, J. Lyu, J. Tang, Highly efficient removal of aqueous $\mathrm{Hg}^{2+}$ and $\mathrm{CH}_{3} \mathrm{Hg}^{+}$by selective modification of biochar with 3mercaptopropyltrimethoxysilane, Chem. Eng. J. 360 (2019) 1646-1655.

[32] H. Zeng, L. Wang, D. Zhang, P. Yan, J. Nie, V.K. Sharma, C. Wang, Highly efficient and selective removal of mercury ions using hyperbranched polyethylenimine functionalized carboxymethyl chitosan composite adsorbent, Chem. Eng. J. 358 (2019) 253-263.

[33] Y.-K. Yang, S.-K. Ko, I. Shin, J. Tae, Synthesis of a highly metal-selective rhodamine-based probe and its use for the in vivo monitoring of mercury, Nat. Protoc. 2 (2007) 1740-1745.

[34] B. Khan, A. Hameed, A. Minhaz, M.R. Shah, Synthesis and characterisation of calix[4]arene based bis(triazole)-bis(hexahydroquinoline): Probing highly selective fluorescence quenching towards mercury $\left(\mathrm{Hg}^{2+}\right)$ analyte, J. Hazard. Mater. 347 (2018) 349-358.

[35] Ma, L., Zhang, X., Ikram, M., Ullah, M., Wu, H., Shi, K. 2020. Controllable synthesis of an intercalated ZIF-67/EG structure for the detection of ultratrace $\mathrm{Cd} 2+, \mathrm{Cu} 2+, \mathrm{Hg} 2+$ and $\mathrm{Pb} 2+$ ions. Chem. Eng. J., 125216.

[36] Liu, S., Feng, D., Zhang, L., Song, H., Wang, Y., Zhang, X., Chen, L. 2020. A reaction-based ratiometric fluorescent probe for mercury ion detection in aqueous solution. Spectrochim. Acta. A, 118817.

[37] Y. Wang, L. Zhang, Y. Huang, X. Wang, L. Zhang, L. Chen, Rational design of a nitroreductase-activatable two-photon fluorescent probe for hypoxia imaging in cell and in vivo, Sensor. Actuat. B - Chem. 310 (2020), 127755.

[38] Y. Wang, X. Wang, L. Zhang, Y. Huang, L. Bi, C. Lv, L. Chen, A ratiometric fluorescent probe for detecting the endogenous biological signaling molecule superoxide anion and bioimaging during tumor treatment, J. Mater. Chem. B 8 (2020) 1017-1025.

[39] G. Qiao, L. Liu, X. Hao, J. Zheng, W. Liu, J. Gao, Q. Wang, Signal transduction from small particles: Sulfur nanodots featuring mercury sensing, cell entry mechanism and in vitro tracking performance, Chem. Eng. J. 382 (2020), 122907.

[40] Y. Wang, L. Zhang, S. Zhang, Z. Liu, L. Chen, High Spatiotemporal Resolution Observation of Glutathione Hydropersulfides in Living Cells and Tissue via a TwoPhoton Ratiometric Fluorescent Probe, Anal. Chem. 91 (2019) 7812-7818.

[41] Y. Wang, X. Han, X. Zhang, L. Zhang, L. Chen, A high selectivity fluorescent probe for hypoxia imaging in cells and tumor-bearing mice model, Analyst. 145 (2020) 1389-1395.

[42] M. Gao, X. Zhang, Y. Wang, Q. Liu, F. Yu, Y. Huang, L. Chen, Sequential detection of superoxide anion and hydrogen polysulfides under hypoxic stress via a spectral-response-separated fluorescent probe functioned with a nitrobenzene derivative, Anal. Chem. 91 (2019) 7774-7781.

[43] Y. Huang, N. He, Y. Wang, L. Zhang, Q. Kang, Y. Wang, L. Chen, Detection of hypochlorous acid fluctuation via a selective near-infrared fluorescent probe in living cells and in vivo under hypoxic stress, J. Mater. Chem. B 7 (2019) 2557-2564.

[44] P. Gao, J. Wang, M. Zheng, Z. Xie, Lysosome targeting carbon dots-based fluorescent probe for monitoring $\mathrm{pH}$ changes in vitro and in vivo, Chem. Eng. J. 381 (2020), 122665.

[45] J. Gu, X. Li, Z. Zhou, R. Liao, J. Gao, Y. Tang, Q. Wang, Synergistic regulation of effective detection for hypochlorite based on a dual-mode probe by employing aggregation induced emission (AIE) and intramolecular charge transfer (ICT) effects, Chem. Eng. J. 368 (2019) 157-164.

[46] N. Mir, A. Heidari, H. Beyzaei, S. Mirkazehi-Rigi, P. Karimi, Detection of $\mathrm{Hg}^{2+}$ in aqueous solution by pyrazole derivative-functionalized $\mathrm{Fe}_{3} \mathrm{O}_{4} @ \mathrm{SiO}_{2}$ fluorescent probe, Chem. Eng. J. 327 (2017) 648-655.
[47] X. Zhang, Y. Xiao, X. Qian, A ratiometric fluorescent probe based on FRET for imaging $\mathrm{Hg}^{2+}$ ions in living cells, Angew. Chem. Int. Edit. 120 (2008) 8145-8149.

[48] X. Guo, X. Qian, L. Jia, A highly selective and sensitive fluorescent chemosensor for $\mathrm{Hg}^{2+}$ in neutral buffer aqueous solution, J. Am. Chem. Soc. 126 (2004) $2272-2273$.

[49] J. Wang, X. Qian, J. Cui, Detecting $\mathrm{Hg}^{2+}$ ions with an ICT fluorescent sensor molecule: remarkable emission spectra shift and unique selectivity, J. Org. Chem. 71 (2006) 4308-4311.

[50] W. Shu, L. Yan, J. Liu, Z. Wang, S. Zhang, C. Tang, B. Du, Highly selective fluorescent probe for the sensitive detection of inorganic and organic mercury species assisted by $\mathrm{H}_{2} \mathrm{O}_{2}$, Ind. Eng. Chem. Res. 54 (2015) 8056-8062.

[51] W. Shu, Y. Wang, L. Wu, Z. Wang, Q. Duan, Y. Gao, L. Yan, Novel carbonothioatebased colorimetric and fluorescent probe for selective detection of mercury ions, Ind. Eng. Chem. Res. 55 (2016) 8713-8718.

[52] Y. Yu, C. Liu, B. Tian, X. Cai, H. Zhu, P. Jia, B. Zhu, A novel highly selective ratiometric fluorescent probe with large emission shift for detecting mercury ions in living cells and zebrafish, Dyes. Pigments 177 (2020), 108290.

[53] B. Zhu, W. Wang, L. Liu, H. Jiang, B. Du, Q. Wei, A highly selective colorimetric and long-wavelength fluorescent probe for $\mathrm{Hg}^{2+}$. Sensor, Actuat. B - Chem. 191 (2014) 605-611.

[54] T. Rasheed, C. Li, F. Nabeel, W. Huang, Y. Zhou, Self-assembly of alternating copolymer vesicles for the highly selective, sensitive and visual detection and quantification of aqueous $\mathrm{Hg}^{2+}$, Chem. Eng. J. 358 (2019) 101-109.

[55] S. Oh, J. Jeon, J. Jeong, J. Park, E.T. Oh, H.J. Park, K.H. Lee, Fluorescent detection of methyl mercury in aqueous solution and live cells using fluorescent probe and micelle systems, Anal. Chem. 92 (2020) 4917-4925.

[56] H.N. Kim, W.X. Ren, J.S. Kim, J. Yoon, Fluorescent and colorimetric sensors for detection of lead, cadmium, and mercury ions, Chem. Soc. Rev. 41 (2012) 3210-3244.

[57] Y. Yang, Q. Zhao, W. Feng, F. Li, Luminescent chemodosimeters for bioimaging, Chem. Rev. 113 (2013) 192-270.

[58] S.H. Park, N. Kwon, J.H. Lee, J. Yoon, I. Shin, Synthetic ratiometric fluorescent probes for detection of ions, Chem. Soc. Rev. 49 (2020) 143-179.

[59] J. Yin, Y. Hu, J. Yoon, Fluorescent probes and bioimaging: alkali metals, alkaline earth metals and pH, Chem. Soc. Rev. 44 (2015) 4619-4644.

[60] Aderinto, S. O. 2020, Fluorescent, colourimetric, and ratiometric probes based on diverse fluorophore motifs for mercuric (II) ion ( $\mathrm{Hg} 2+$ ) sensing: highlights from 2011 to 2019. Chem Pap-Chem Zvesti, 1.

[61] P. Mahato, S. Saha, P. Das, H. Agarwalla, A. Das, An overview of the recent developments on $\mathrm{Hg}^{2+}$ recognition, RSC Adv. 4 (2014) 36140-36174.

[62] A. Ono, H. Togashi, Highly selective oligonucleotide-based sensor for mercury(II) in aqueous solutions, Angew. Chem. 43 (2004) 4300-4302.

[63] Z. Wang, D.Q. Zhang, D.B. Zhu, A sensitive and selective "turn on" fluorescent chemosensor for $\mathrm{Hg}$ (II) ion based on a new pyrene-thymine dyad, Anal. Chim. Acta. 549 (2005) 10-13.

[64] C.-K. Chiang, C.-C. Huang, C.-W. Liu, H.-T. Chang, Oligonucleotide-based fluorescence probe for sensitive and selective detection of mercury(II) in aqueous solution, Anal. Chem. 80 (2008) 3716-3721.

[65] A. Banerjee, D. Karak, A. Sahana, S. Guha, S. Lohar, D. Das, Methionine-pyrene hybrid based fluorescent probe for trace level detection and estimation of $\mathrm{Hg}$ (II) in aqueous environmental samples: Experimental and computational studies, J. Hazard. Mater. 186 (2011) 738-744.

[66] K.M. Vengaian, C.D. Britto, K. Sekar, G. Sivaraman, S. Singaravadivel, Phenothiazine-diaminomalenonitrile based Colorimetric and Fluorescence "Turnoff-on" Sensing of $\mathrm{Hg}^{2+}$ and S"-, Sensor. Actuat. B-Chem. 235 (2016) 232-240.

[67] M. Shyamal, S. Maity, A. Maity, R. Maity, S. Roy, A. Misra, Aggregation induced emission based "turn-off" fluorescent chemosensor for selective and swift sensing of mercury (II) ions in water, Sensor. Actuat. B-Chem. 263 (2018) 347-359.

[68] Zhou, G., Zhang, X. and Ni, X.-L., 2020. Tuning the amphiphilicity of terpyridinebased fluorescent probe in water: Assembly and disassembly-controlled $\mathrm{Hg}(2+)$ sensing, removal, and adsorption of H2S. J. Hazard. Mater. 384.

[69] Zhao, L., Zhang, Z., Liu, Y., Wei, J., Liu, Q., Ran, P. and Li, X., 2020. Fibrous strips decorated with cleavable aggregation-induced emission probes for visual detection of $\mathrm{Hg} 2+$. J. Hazard. Mater. 385.

[70] A.B. Descalzo, R. Martinez-Manez, R. Radeglia, K. Rurack, J. Soto, Coupling selectivity with sensitivity in an integrated chemosensor framework: Design of a $\mathrm{Hg}^{2+}$-responsive probe, operating above $500 \mathrm{~nm}$, J. Am. Chem. Soc. 125 (2003) 3418-3419.

[71] R. Koteeswari, P. Ashokkumar, E.J.P. Malar, V.T. Ramakrishnan, P. Ramamurthy, Highly selective, sensitive and quantitative detection of $\mathrm{Hg}^{2+}$ in aqueous medium under broad pH range, Chem. Commun. 47 (2011) 7695-7697.

[72] J. Hu, Z. Hu, Z. Chen, H.-W. Gao, K. Uvdal, A logic gate-based fluorogenic probe for $\mathrm{Hg}^{2+}$ detection and its applications in cellular imaging, Anal. Chim. Acta. 919 (2016) 85-93.

[73] Y.K. Yang, K.J. Yook, J. Tae, A rhodamine-based fluorescent and colorimetric chemodosimeter for the rapid detection of $\mathrm{Hg}^{2+}$ ions in aqueous media, J. Am. Chem. Soc. 127 (2005) 16760-16761.

[74] S.-K. Ko, Y.-K. Yang, J. Tae, I. Shin, In vivo monitoring of mercury ions using a rhodamine-based molecular probe, J. Am. Chem. Soc. 128 (2006) 14150-14155.

[75] X.-Q. Zhan, Z.-H. Qian, H. Zheng, B.-Y. Su, Z. Lan, J.-G. Xu, Rhodamine thiospirolactone. Highly selective and sensitive reversible sensing of $\mathrm{Hg}(\mathrm{II})$, Chem. Commun. 16 (2008) 1859-1861.

[76] W. Lin, X. Cao, Y. Ding, L. Yuan, L. Long, A highly selective and sensitive fluorescent probe for $\mathrm{Hg}^{2+}$ imaging in live cells based on a rhodamine-thioamidealkyne scaffold, Chem. Commun. 46 (2010) 3529-3531. 
[77] Q.-J. Ma, X.-B. Zhang, X.-H. Zhao, Z. Jin, G.-J. Mao, G.-L. Shen, R.-Q. Yu, A highly selective fluorescent probe for $\mathrm{Hg}^{2+}$ based on a rhodamine-coumarin conjugate, Anal. Chim. Acta. 663 (2010) 85-90.

[78] S. Mandal, A. Banerjee, S. Lohar, A. Chattopadhyay, B. Sarkar, S. K. Mukhopadhyay, A. Sahana, D. Das, Selective sensing of $\mathrm{Hg}^{2+}$ using rhodaminethiophene conjugate: Red light emission and visual detection of intracellular $\mathrm{Hg} 2$ + at nanomolar level, J. Hazard. Mater. 261 (2013) 198-205.

[79] K. Bera, A.K. Das, M. Nag, S. Basak, Development of a Rhodamine-RhodanineBased Fluorescent Mercury Sensor and Its Use to Monitor Real-Time Uptake and Distribution of Inorganic Mercury in Live Zebrafish Larvae, Anal. Chem. 86 (2014) 2740-2746.

[80] M. Hong, X. Lu, Y. Chen, D. Xu, A novel rhodamine-based colorimetric and fluorescent sensor for $\mathrm{Hg}^{2+}$ in water matrix and living cell, Sensor. Actuat. BChem. 232 (2016) 28-36.

[81] D. Li, C.-Y. Li, Y.-F. Li, Z. Li, F. Xu, Rhodamine-based chemodosimeter for fluorescent determination of $\mathrm{Hg}^{2+}$ in $100 \%$ aqueous solution and in living cells, Anal. Chim. Acta. 934 (2016) 218-225.

[82] J. Wang, W. Li, L. Long, Development of a near-infrared fluorescence turn-on probe for imaging $\mathrm{Hg}^{2+}$ in living cells and animals, Sensor. Actuat. B-Chem. 245 (2017) 462-469.

[83] Y. Yang, R. Shen, Y.-Z. Wang, F.-Z. Qiu, Y. Feng, X.-L. Tang, D.-C. Bai, G.L. Zhang, W.-S. Liu, A selective turn-on fluorescent sensor for $\mathrm{Hg}$ (II) in living cells and tissues, Sensor. Actuat. B-Chem. 255 (2018) 3479-3487.

[84] Y. Chen, C. Zhu, Z. Yang, J. Li, Y. Jiao, W. He, J. Chen, Z. Guo, A new "turn-on" chemodosimeter for $\mathrm{Hg}^{2+}$ : ICT fluorophore formation via $\mathrm{Hg}^{2+}$-induced carbaldehyde recovery from 1,3-dithiane, Chem. Commun. 48 (2012) 5094-5096.

[85] Z. Zhang, B. Zhang, X. Qian, Z. Li, Z. Xu, Y. Yang, Simultaneous Quantification of $\mathrm{Hg}^{2+}$ and $\mathrm{MeHg}^{+}$in Aqueous Media with a Single Fluorescent Probe by Multiplexing in the Time Domain, Anal. Chem. 86 (2014) 11919-11924.

[86] C. Song, W. Yang, N. Zhou, R. Qian, Y. Zhang, K. Lou, R. Wang, W. Wang, Fluorescent theranostic agents for $\mathrm{Hg}^{2+}$ detection and detoxification treatment, Chem. Commun. 51 (2015) 4443-4446.

[87] G. Hennrich, H. Sonnenschein, U. Resch-Genger, Redox switchable fluorescent probe selective for either $\mathrm{Hg}$ (II) or Cd(II) and Zn(II), J. Am. Chem. Soc. 121 (1999) 5073-5074.

[88] E.M. Nolan, S.J. Lippard, Turn-on and ratiometric mercury sensing in water with a red-emitting probe, J. Am. Chem. Soc. 129 (2007) 5910-5918.

[89] H.-W. Li, Y. Li, Y.-Q. Dang, L.-J. Ma, Y. Wu, G. Hou, L. Wu, An easily prepared hypersensitive water-soluble fluorescent probe for mercury(II) ions, Chem. Commun. 29 (2009) 4453-4455.

[90] Y. Xu, Z. Jiang, Y. Xiao, T.-T. Zhang, J.-Y. Miao, B.-X. Zhao, A new fluorescent turn-on chemodosimeter for mercury ions in solution and its application in cells and organisms, Anal. Chim. Acta. 807 (2014) 126-134.

[91] Q. Duan, H. Zhu, C. Liu, R. Yuan, Z. Fang, Z. Wang, P. Jia, Z. Li, W. Sheng, B. Zhu, A carbonothioate-based far-red fluorescent probe for the specific detection of mercury ions in living cells and zebrafish, Analyst. 144 (2019) 1426-1432.

[92] U. Haldar, H.-I. Lee, BODIPY-Derived Polymeric Chemosensor Appended with Thiosemicarbazone Units for the Simultaneous Detection and Separation of $\mathrm{Hg}(\mathrm{II})$ Ions in Pure Aqueous Media, Acs Appl. Mater. Inter. 11 (2019) 13685-13693.

[93] S. Yoon, A.E. Albers, A.P. Wong, C.J. Chang, Screening mercury levels in fish with a selective fluorescent chemosensor, J. Am. Chem. Soc. 127 (2005) 16030-16031.

[94] C.S. Lim, D.W. Kang, Y.S. Tian, J.H. Han, H.L. Hwang, B.R. Cho, Detection of mercury in fish organs with a two-photon fluorescent probe, Chem. Commun. 46 (2010) 2388-2390.

[95] P. Srivastava, S.S. Razi, R. Ali, R.C. Gupta, S.S. Yadav, G. Narayan, A. Misra, Selective Naked-Eye Detection of $\mathrm{Hg}^{2+}$ through an Efficient Turn-On Photoinduced Electron Transfer Fluorescent Probe and Its Real Applications, Anal. Chem. 86 (2014) 8693-8699.

[96] H. Xiao, J. Li, K. Wu, G. Yin, Y. Quan, R. Wang, A turn-on BODIPY-based fluorescent probe for $\mathrm{Hg}(\mathrm{II})$ and its biological applications, Sensor. Actuat. BChem. 213 (2015) 343-350.

[97] G.G.V. Kumar, M.P. Kesavan, A. Tamilselvi, G. Rajagopal, J.D. Raja, K. Sakthipandi, J. Rajesh, G. Sivaraman, A reversible fluorescent chemosensor for the rapid detection of $\mathrm{Hg}^{2+}$ in an aqueous solution: Its logic gates behavior, Sensor. Actuat. B-Chem. 273 (2018) 305-315.

[98] S. Ando, K. Koide, Development and Applications of Fluorogenic Probes for Mercury(II) Based on Vinyl Ether Oxymercuration, J. Am. Chem. Soc. 133 (2011) 2556-2566.

[99] C. Wu, J. Wang, J. Shen, C. Bi, H. Zhou, Coumarin-based $\mathrm{Hg}^{2+}$ fluorescent probe: Synthesis and turn-on fluorescence detection in neat aqueous solution, Sensor. Actuat. B-Chem. 243 (2017) 678-683.

[100] B. Yuan, D.-X. Wang, L.-N. Zhu, Y.-L. Lan, M. Cheng, L.-M. Zhang, J.-Q. Chu, X.Z. Li, D.-M. Kong, Dinuclear Hg-II tetracarbene complex-triggered aggregationinduced emission for rapid and selective sensing of $\mathrm{Hg}^{2+}$ and organomercury species, Chem. Sci. 10 (2019) 4220-4226.

[101] L.N. Neupane, J. Park, P.K. Mehta, E.-T. Oh, H.J. Park, K.-H. Lee, Fast and sensitive fluorescent detection of inorganic mercury species and methylmercury using a fluorescent probe based on the displacement reaction of arylboronic acid with the mercury species, Chem. Commun. 56 (2020) 2941-2944.

[102] B. Liu, H. Tian, A selective fluorescent ratiometric chemodosimeter for mercury ion, Chem. Commun. 25 (2005) 3156-3158.

[103] M. Tian, H. Ihmels, Selective ratiometric detection of mercury(II) ions in water with an acridizinium-based fluorescent probe, Chem. Commun. 22 (2009) 3175-3177.

[104] W. Xuan, C. Chen, Y. Cao, W. He, W. Jiang, K. Liu, W. Wang, Rational design of a ratiometric fluorescent probe with a large emission shift for the facile detection of $\mathrm{Hg}^{2+}$, Chem. Commun. 48 (2012) 7292-7294.

[105] L. Chen, S.J. Park, D. Wu, H.M. Kim, J. Yoon, A two-photon fluorescent probe for colorimetric and ratiometric monitoring of mercury in live cells and tissues, Chem. Commun. 55 (2019) 1766-1769.

[106] X. Cheng, Q. Li, J. Qin, Z. Li, A New Approach to Design Ratiometric Fluorescent Probe for Mercury(II) Based on the $\mathrm{Hg}^{2+}$-Promoted Deprotection of Thioacetals, Acs Appl. Mater. Inter. 2 (2010) 1066-1072.

[107] Y. Zhou, X. He, H. Chen, Y. Wang, S. Xiao, N. Zhang, D. Li, K. Zheng, An ESIPT/ ICT modulation based ratiometric fluorescent probe for sensitive and selective sensing $\mathrm{Hg}^{2+}$, Sensor. Actuat. B-Chem. 247 (2017) 626-631.

[108] L. Lan, Q. Niu, T. Li, A highly selective colorimetric and ratiometric fluorescent probe for instantaneous sensing of $\mathrm{Hg}^{2+}$ in water, soil and seafood and its application on test strips, Anal. Chim. Acta. 1023 (2018) 105-114.

[109] S.-L. Pan, K. Li, L.-L. Li, M.-Y. Li, L. Shi, Y.-H. Liu, X.-Q. Yu, A reaction-based ratiometric fluorescent sensor for the detection of $\mathrm{Hg}(\mathrm{II})$ ions in both cells and bacteria, Chem. Commun. 54 (2018) 4955-4958.

[110] Z. Ruan, Y. Shan, Y. Gong, C. Wang, F. Ye, Y. Qiu, Z. Lianga, Z. Li, Novel AIEactive ratiometric fluorescent probes for mercury(II) based on the $\mathrm{Hg}^{2+}$-promoted deprotection of thioketal, and good mechanochromic properties, J. Mater. Chem. C. 6 (2018) 773-780.

[111] X. Zhang, Y. Xiao, X. Qian, A Ratiometric Fluorescent Probe Based on FRET for Imaging $\mathrm{Hg}^{2+}$ Ions in Living Cells, Angew. Chem. Int. Ed. 47 (2008) 8025-8029.

[112] Y. Ge, A. Liu, R. Ji, S. Shen, X. Cao, Detection of $\mathrm{Hg}^{2+}$ by a FRET ratiometric fluorescent probe based on a novel pyrido 1,2-a benzimidazole-rhodamine system, Sensor. Actuat. B Chem. 251 (2017) 410-415.

[113] Y. Li, S. Qi, C. Xia, Y. Xu, G. Duan, Y. Ge, A FRET ratiometric fluorescent probe for detection of $\mathrm{Hg}^{2+}$ based on an imidazo 1,2-a pyridine-rhodamine system, Anal. Chim. Acta. 1077 (2019) 243-248.

[114] Y. Chen, W. Zhang, Y. Cai, R.T.K. Kwok, Y. Hu, J.W.Y. Lam, X. Gu, Z. He, Z. Zhao, X. Zheng, B. Chen, C. Gui, B.Z. Tang, AIEgens for dark through-bond energy transfer: design, synthesis, theoretical study and application in ratiometric $\mathrm{Hg}^{2+}$ sensing, Chem. Sci. 8 (2017) 2047-2055.

[115] C.-Y. Li, X.-B. Zhang, L. Qiao, Y. Zhao, C.-M. He, S.-Y. Huan, L.-M. Lu, L.-X. Jian, G.-L. Shen, R.-Q. Yu, Naphthalimide-Porphyrin Hybrid Based Ratiometric Bioimaging Probe for $\mathrm{Hg}^{2+}$ : Well-Resolved Emission Spectra and Unique Specificity, Anal. Chem. 81 (2009) 9993-10001.

[116] J. Jiang, W. Liu, J. Cheng, L. Yang, H. Jiang, D. Bai, W. Liu, A sensitive colorimetric and ratiometric fluorescent probe for mercury species in aqueous solution and living cells, Chem. Commun. 48 (2012) 8371-8373.

[117] Y. Jiao, X. Liu, L. Zhou, H. He, P. Zhou, C. Duan, A schiff-base dual emission ratiometric fluorescent chemosensor for $\mathrm{Hg}^{2+}$ ions and its application in cellular imaging, Sensor. Actuat. B-Chem. 247 (2017) 950-956.

[118] Y. Chen, L. Wan, X. Yu, W. Li, Y. Bian, J. Jiang, Rational Design and Synthesis for Versatile FRET Ratiometric Sensor for $\mathrm{Hg}^{2+}$ and $\mathrm{Fe}^{2+}$ : A Flexible 8-Hydroxyquinoline Benzoate Linked Bodipy-Porphyrin Dyad, Organ. Lett. 13 (2011) 5774-5777.

[119] B.-X. Shen, Y. Qian, A novel triphenylamine-BODIPY dendron: click synthesis, near-infrared emission and a multi-channel chemodosimeter for $\mathrm{Hg}^{2+}$ and $\mathrm{Fe}^{3+}$, J. Mater. Chem. B. 4 (2016) 7549-7559.

[120] Y. Gao, C. Zhang, S. Peng, H. Chen, A fluorescent and colorimetric probe enables simultaneous differential detection of $\mathrm{Hg}^{2+}$ and $\mathrm{Cu}^{2+}$ by two different mechanisms, Sensor. Actuat. B-Chem. 238 (2017) 455-461.

[121] B. Gu, L. Huang, W. Su, X. Duan, H. Li, S. Yao, A benzothiazole-based fluorescent probe for distinguishing and bioimaging of $\mathrm{Hg}^{2+}$ and $\mathrm{Cu}^{2+}$, Anal. Chim. Acta. 954 (2017) 97-104.

[122] Z.-Q. Hu, C.-S. Lin, X.-M. Wang, L. Ding, C.-L. Cui, S.-F. Liu, H.Y. Lu, Highly sensitive and selective turn-on fluorescent chemosensor for $\mathrm{Pb}^{2+}$ and $\mathrm{Hg}^{2+}$ based on a rhodamine-phenylurea conjugate, Chem. Commun. 46 (2010) 3765-3767.

[123] K. Tsukamoto, Y. Shinohara, S. Iwasaki, H. Maeda, A coumarin-based fluorescent

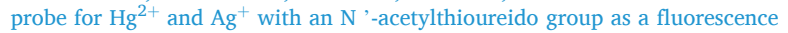
switch, Chem. Commun. 47 (2011) 5073-5075.

[124] E. Karakus, M. Ucuncu, M. Emrullahoglu, A rhodamine/BODIPY-based fluorescent probe for the differential detection of $\mathrm{Hg}(\mathrm{II})$ and $\mathrm{Au}(\mathrm{III})$, Chem. Commun. 50 (2014) 1119-1121.

[125] S. Erdemir, Fluorometric dual sensing of $\mathrm{Hg}^{2+}$ and $\mathrm{Al}^{3+}$ by novel triphenylamine appended rhodamine derivative in aqueous media, Sensor. Actuat. B-Chem. 290 (2019) 558-564.

[126] J. Hu, T. Liu, H.-W. Gao, S. Lu, K. Uvdal, Z. Hu, Selective detections of $\mathrm{Hg}^{2+}$ and Fby using tailor-made fluorogenic probes, Sensor. Actuat. B-Chem. 269 (2018) 368-376. 